\title{
Ecología de poblaciones de plantas en una selva húmeda de México
}

\author{
MIGUEL MARTÍNEZ RAMOS Y ELENA ÁLVAREZ BUYLLA \\ Centro de Ecología, UNAM, Apdo Postal 70-725, México, D.F., 04510, México
}

\begin{abstract}
Resumen. Se presenta una revisión y análisis de los estudios de ecología de poblaciones de plantas realizados en selvas húmedas de México, particularmente en la Estación de Biología Tropical Los Tuxtlas (UNAM); se abordan los siguientes temas: (i) patrones estructurales y demográficos, (ii) análisis de la dinámica de poblaciones, (iii) exploración de la evolución de historias de vida y (iv) demografía, conservación y manejo de recursos naturales. Los estudios muestran un considerable avance en la descripción de patrones, en el análisis de la dinámica de poblaciones y en la detección de algunos aspectos demográficos que pueden ser claves para los propósitos de la conservación y manejo de recursos. Sin embargo, el nivel de entendimiento de las causas que originan tales patrones y dinámicas es aún pobre. Los estudios han centrado su interés principalmente en poblaciones de árboles que son abundantes; otras formas de vida y especies que son raras han recibido una atención virtualmente nula. Después de sintetizar los puntos emergentes de la presente revisión, indicamos algunas perspectivas que creemos que serán importantes de seguir en el futuro.
\end{abstract}

Palabras clave: conservación, demografía de plantas, Los Tuxtlas, selva alta perennifolia.

Abstract. This paper reviewing plant population ecology studies that have done in Mexican tropical rain forests, particularly at the Los Tuxtlas Tropical Field Station (UNAM). The review considers next topics: (i) population structure and demographic patterns, (ii) population dynamics, (iii) life-history evolution, and (iv) the importance of demography and genetics for conservation and management of tropical rain forest plant products. The studies show an important advance in the description of patterns, in the analysis of population dynamics, and in the detection of some key demographic elements that can be important for forest conservation and management. However, the understanding of causes that originate such patterns and dynamics is yet poor. The studies have focused mainly on abundant arboreal plant species; other plant life-forms and rare species have received virtually null attention. After pointing out conclusions gained from our review, we propose some perspectives for future research.

Key words: conservation, plant demography, Los Tuxtlas, tropical rainforest.

\section{INTRODUCCIÓN}

"Mirese una planta que se encuentra en el centro de la región que abarca su especie, por qué no duplica o cuadruplica su número?... si deseamos dar con la imaginación a esa planta el poder de aumentar en número, tenemos que ofrecerle alguna ventaja sobre sus competidoras o sobre los animales que la comen» (Darwin, 1857).

Un árbol de Cecropia obtusifolia, especie típica de selvas húmedas del sureste de México, alcanza en menos de tres años la madurez y produce anualmente alrededor de 10 millones de semillas que son ampliamente dispersadas por una gran variedad de aves y mamíferos frugívoros (Estrada et al., 1984; Álvarez-Buylla y Martínez-Ramos, 1990, 1992). Si cada una de estas semillas tuviese una dispersión ilimitada, pudiese desarrollarse hasta producir la misma cantidad de semillas y este proceso se repitiera cada año, en menos de cinco décadas $C$. obtusifolia cubriría toda la Tierra. Sin embargo, estos árboles se encuentran sólo en algunas áreas tropicales y no son los más abundantes en estas regiones. Condiciones adversas, la falta de recursos, la presencia de enemigos naturales letales, o la ausencia de dispersores de semillas, impiden a $C$. obtusifolia capitalizar su potencial reproductivo en las diferentes regiones del planeta. Tal caso de limitación en abundancia y distribución opera sobre cualquier especie y la explicación a este fenómeno constituye el propósito principal de estudio de la ecología de poblaciones.

Gran parte del conocimiento que se tiene en México sobre la ecología de poblaciones de plantas de selvas húmedas, proviene de los estudios realizados en la Estación de Biología Tropical Los Tuxtlas (Córdova, 1985). La Estación se encuentra ubicada al sureste del estado de Veracruz, en la región de Los Tuxtlas (Estrada et al., 1985), donde actualmente la selva alta perennifolia alcanza su límite de distribución más norteña en América (Dirzo y Miranda, 1991). En este artículo revisaremos los frutos de los estudios de ecología de poblaciones en selvas húmedas de México y discutiremos algunas de las aportaciones científicas y prácticas de los mismos. Lo hemos dividido en seis secciones. Las dos primeras describen características estructurales y patrones demográficos de las poblaciones. La tercera y la cuarta tratan sobre aspectos de la dinámica de las poblaciones y de la evolución de atributos dienográficos (que en conjunto son conocidos como historias de vida). La quinta sección aborda 
brevemente ejemplos de las posibles contribuciones de los estudios poblacionales hacia los campos de la conservación y manejo de recursos. Finalmente, la última sección resume conclusiones y posibles perspectivas de estudio que emergen de la presente revisión.

\section{ESTRUCTURA DE LAS POBLACIONALES}

Un marco conceptual útil en el análisis de la variabilidad ambiental que afecta a las poblaciones de plantas de selvas húmedas, es el modelo del ciclo de regeneración natural o dinámica de parches (Denslow, 1987). La caída de ramas y árboles abre claros en el dosel de la selva, provocando importantes cambios ambientales en el interior del bosque (Brokaw, 1985). Estos cambios afectan las probabilidades de germinación, establecimiento y/o reproducción de las plantas (Martínez-Ramos et al., 1989). Con la apertura de un claro se inicia el ciclo de regeneración natural (Hartshorn, 1978; Brokaw, 1985; Martínez-Ramos, 1985). En los claros grandes $\left(>100 \mathrm{~m}^{2}\right)$ el crecimiento rápido de la vegetación conduce, después de varias décadas, al establecimiento de nuevos árboles maduros en el dosel (Whitmore, 1982). Con el tiempo, la caída de otro árbol reinicia el ciclo. El proceso de reemplazamiento de árboles produce un mosaico de distintas fases regenerativas en la comunidad de plantas, que difieren en estructura, composición de especies y situaciones ambientales (Denslow, 1987).

\section{Patrones de distribución}

La heterogeneidad ambiental presente en el mosaico de regeneración afecta la densidad y la distribución espacial de las poblaciones (Hubbell y Foster 1983, 1987). Por ejemplo, en la selva de Los Tuxtlas, las poblaciones de plantas herbáceas como las de Dieffenbachia seguine (Araceae), Heliconia uxpanapensis (Musaceae), Schaueria calycobractea (Acanthacea) y Xantosoma robustum (Araceae) abundan en los claros, mientras que casi no se encuentran en las áreas sombreadas del bosque. El caso contrario ocurre con poblaciones de especies como Anthurium flexile (Araceae), Aphelandra aurantiaca (Acanthaceae) y Spathiphyllum cochlearispathum (Araceae), plantas que pueden desarollarse de manera abundante también en la sombra (Calvo, 1989; Dirzo et al., 1992).

En la misma selva, la palma Astrocaryum mexicanum llega a poseer más de 1,000 individuos adultos por hectárea (Piñero et al., 1984), y se distribuyen a través de todo el mosaico de regeneración. Las diásporas producidas por estas palmas tienen muy baja dispersabilidad y sufren un alto nivel de depredación (más del 95\%). No obstante, las pocas semillas que sobreviven dan lugar a plántulas que tienen muy altas probabilidades de establecerse y llegar a la reproducción bajo cualquier situación ambiental del mosaico (Sarukhán, 1980; Martínez-Ramos et al., 1988a).

Pseudolmedia oxyphyllaria (Moraceae), que es una de las especies arbóreas (altura máxima entre 20 y $25 \mathrm{~m}$ ) de mayor densidad poblacional en la selva de Los Tuxtlas
(Bongers et al., 1988), tiene también una amplia distribución en el mosaico de regeneración (Fig. 1). Las drupas rojas, dulces y carnosas que produce son alimento de aves, murciélagos y mamíferos arborícolas. Estos animales pueden dispersar ampliamente las semillas, y las plántulas puede crecer bajo todas las fases regenerativas de la selva (Popma y Bongers, 1988). Los mamíferos (ratones, ardillas y tepezcuintles) depredan las semillas de manera intensa bajo la copa de los árboles reproductivos y diluyen la agregación de individuos en la población (Martínez-Ramos, Rodríguezy Dyer, datos no publicados). El caso de Astrocaryum mexicanum y el de $P$. oxyphyllaria sugieren que una sobrevivencia elevada y la capacidad para crecer bajo cualquier condición ambiental del mosaico de regeneración, son determinantes importantes de la densidad y distribución de las plantas en las selvas húmedas.

Algunas poblaciones con elevada densidad poblacional, como aquellas de Nectandra ambigens (Lauraceae), Omphalea oleifera (Euphorbiaceae), Cecropia obtusifolia (Moraceae) y Heliocarpus appendiculatus (Tiliaceae) no se distribuyen a través de todo el mosaico de regeneración y tienen un patrón espacial agregado (Fig. 1). La agregación puede responder a una pobre dispersión y bajos niveles de depredación de semillas, como ocurre con $N$. ambigens (Córdova, 1985) y, sobre todo, con O. oleifera (Palomeque, 1988). Estos árboles producen frutos con semillas grandes (de 2-4 cm de diámetro) que al madurar caen, en su mayoría, bajo la copa del progenitor, donde menos del $50 \%$ de las semillas son depredadas (Córdova, 1985; Palomeque, 1988). La agregación presente en las poblaciones de Cecropia obtusifolia y Heliocarpus appendiculatus se debe a que estos árboles germinan y maduran sólo en los claros de la selva, los cuales son espacialmente infrecuentes (Núñez-Farfán y Dirzo, 1988; Álvarez-Buylla y Martínez-Ramos, 1992).

La mayoría de las especies arbóreas de las selvas húmedas presentan densidades poblacionales bajas, con frecuencia de menos de un individuo adulto por hectárea (Hubbell y Foster, 1983; Bongers et al., 1988; Gentry, 1990). En Los Tuxtlas, más del $70 \%$ de las poblaciones de plantas arbóreas, arbustivas y herbáceas, tanto muy demandantes de luz como tolerantes a la sombra, que fueron censadas en una superficie de 5 ha (Martínez-Ramos y Álvarez-Buylla, datos no publicados), presentaron densidades menores que dos individuos por hectárea (Fig. 2). Con frecuencia, las poblaciones de baja densidad son hábitatespecialistas, de modo que ocurren asociadas con fases regenerativas de la selva poco frecuentes (tales como los claros), o bien con situaciones topográficas y suelos muy particulares (Hubbell y Foster, 1986a, 1987, 1990a). Un proceso de extinción local, o bien el inicio de un proceso de colonización y crecimiento, puede explicar la rareza poblacional de otras especies (Hubbell y Foster, 1986).

\section{Estructura de tamaños (edades)}

En algunos casos, el tamaño de una planta varía de manera positiva y estrecha con su edad (Sarukhán, 1978, 1980; 
Arboles fuertemente demandates de luz Número de árboles en 5 ha

Cecropia obtus:folia Heliocarpus appendiculatus. Erytrina folkersi Rollinia jimente Carica papaya um mexicanum Hampea nutricea Cnidosculus multilobus Hamelia iongipe Hamelia paien Cestrum racemosum

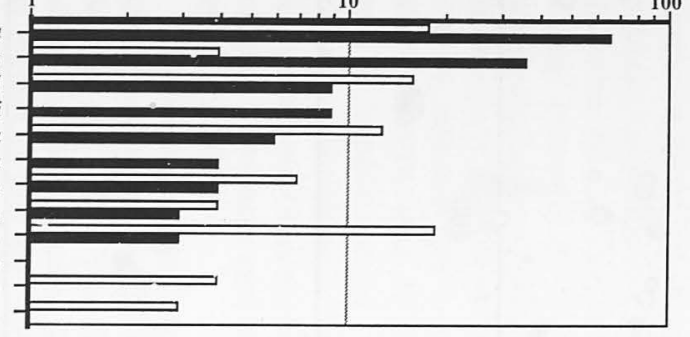
100

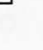

.

Arbutos y herbáceas

Número de plantas en 5 ha

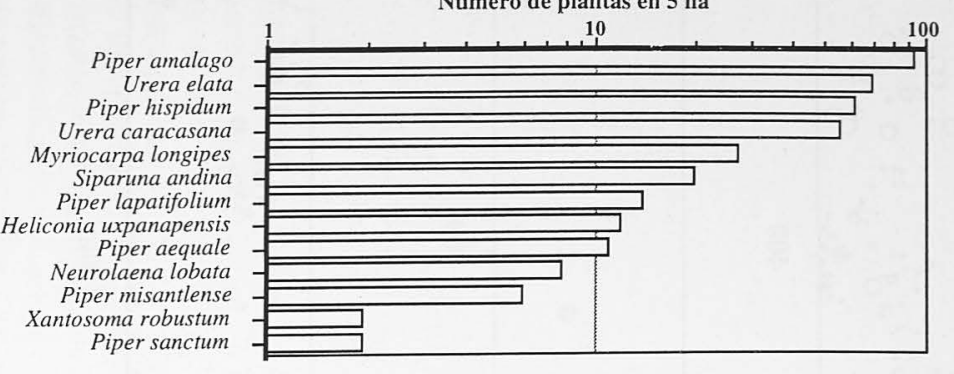

Arboles del dosel superior

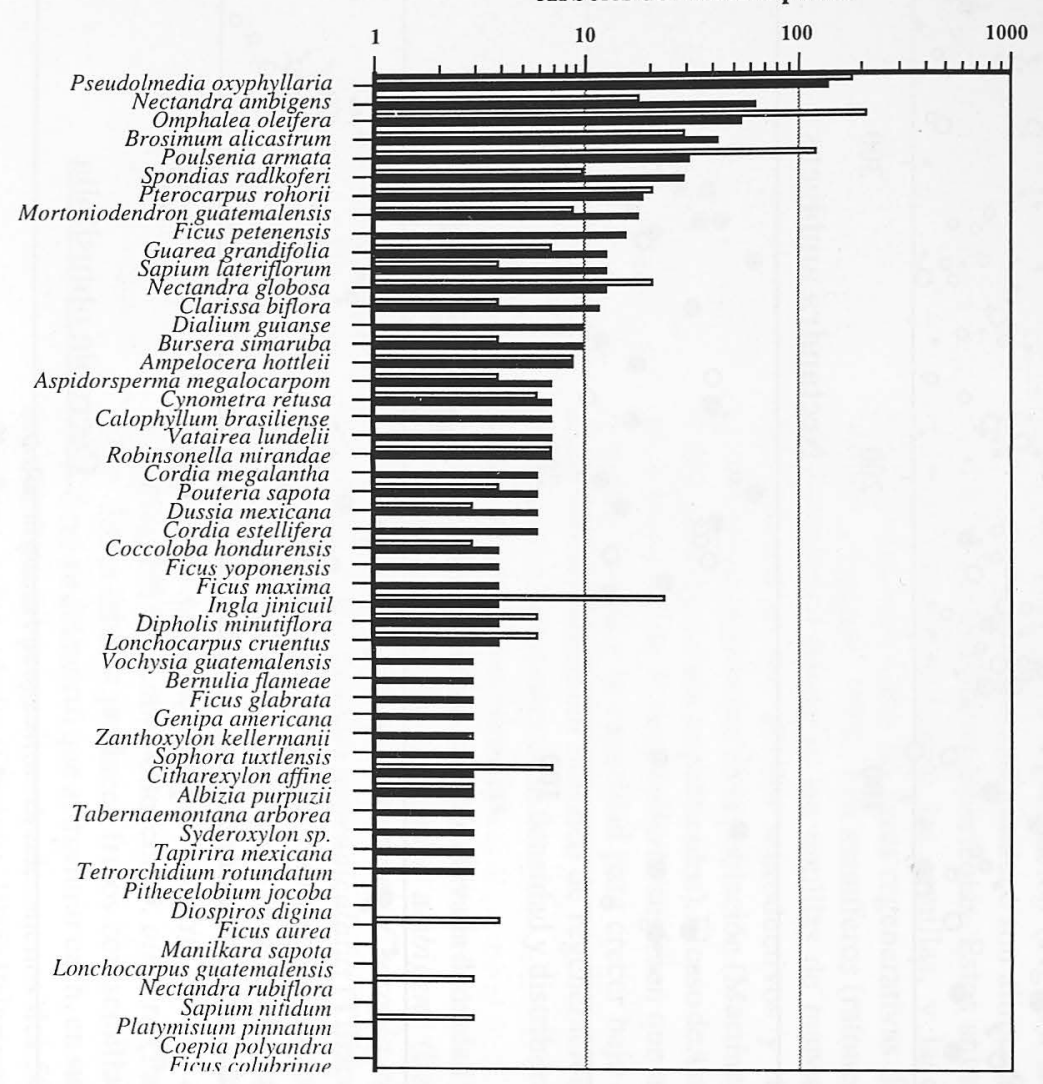

Arboles del dosel bajo y medio

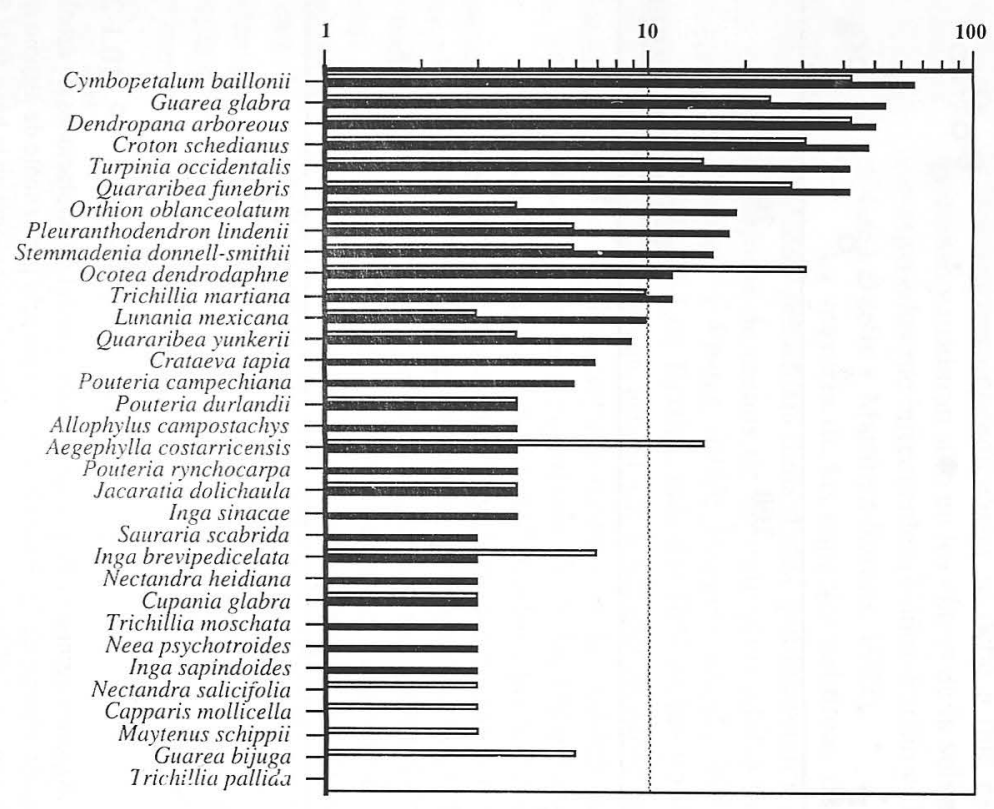

100

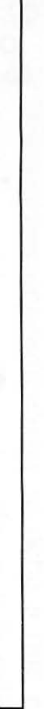

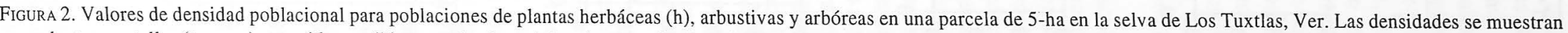

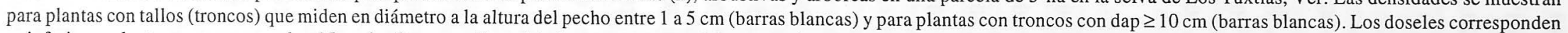
a: inferior = plantas que no pasan los $15 \mathrm{~m}$ de altura, medio = árboles que no pasan $25 \mathrm{~m}$, superior = árboles que sobrepasan los $25 \mathrm{~m}$. 
Lieberman et al., 1985a; Álvarez-Buylla y Martínez-Ramos, 1992). Con más frecuencia, la relación tamaño-edad es muy débil o no existe, debido a que las plantas varían notablemente en tamaño dependiendo de las circunstancias ambientales (Harper, 1977). Por ejemplo, en Panamá, plántulas del árbol Tachigalia versicolor (Myristicaceae) crecieron 30-60 cm de altura en 30 años bajo condiciones de sombra, mientras que otras de la misma cohorte crecieron más de 5 m en claros del bosque (R. Foster, comunicación personal). Individuos de Cecropia obtusifolia con un mismo tamaño pueden diferir más de dos veces en edad, dependiendo de la situación lumínica que afecta a cada individuo dentro de los claros (Álvarez-Buylla y Martínez-Ramos, 1992). Por lo tanto, la estructura de tamaños de una población refleja la composición de edades, la frecuencia de parches de diferente calidad ambiental o, lo más probable, una combinación de estas dos posibilidades. En general, se pueden distinguir en las poblaciones de plantas de selvas húmedas tres tipos de estructuras de tamaños (Bongers et al., 1988):

Tipo I. Disminución de la frecuencia de individuos con el aumento en el tamaño. Esta estructura puede tener dos posibles orígenes extremos. 1) Suponiendo que existe una estrecha relación positiva tamaño-edad, una alta frecuencia de individuos pequeños (jóvenes) reflejaría que los micrositios favorables para el nacimiento y desarrollo inicial de los individuos son abundantes. Una tasa de mortalidad que disminuye con la edad o que es constante a través del ciclo de vida, produciría la disminución de individuos de edades cada vez mayores. 2) Si la relación tamaño-edad no existe y los individuos crecen a ritmos distintos dependiendo de la situación ambiental que afecta a cada individuo, una estructura de tamaños predominada por árboles pequeños indicaría que existen muchos más sitios pobres que buenos para el crecimiento de los individuos. Aun poblaciones coetáneas, que crecen bajo ambientes predominantemente desfavorables, podrían mostrar este tipo de estructura poblacional.

Tipo II. Mayor frecuencia de individuos grandes que pequeños. Suponiendo que existe una estrecha relación tamaño-edad, esta estructura podría ser el resultado de fuertes limitantes ambientales al establecimiento y sobrevivencia de los individuos de edades tempranas. Si la población fuese coetánea, esta estructura sugeriría que los individuos crecen a ritmos similares. En cualquiera de los dos casos, esta estructura puede reflejar que las situaciones ambientales específicas, y/o los eventos reproductivos, que favorecen el ingreso de nuevos individuos en la población, ocurren de manera intermitente (pulsar).

Tipo III. Mayor frecuencia de individuos de tallas pequeñas y grandes que intermedias. Tal estructura puede tener varios orígenes. 1) Dos eventos pulsares de nacimientos (como a los que se hizo referencia en el párrafo anterior) componen a la población; los individuos grandes reflejan un evento de reclutamiento más antiguo que los individuos pequeños. 2) La transición de individuos de un tamaño pequeño a uno mayor ocurre sólo bajo situaciones ambientales que se dan de manera infrecuente en el tiempo. 3) La tasa de mortalidad no es constante con el tamaño de los individuos; es mayor en los de tallas intermedias. 3) La tasa de mortalidad es independiente del tamaño pero los individuos tienen su máxima tasa de crecimiento al alcanzar una talla (intermedia) crítica.

La Fig. 3 muestra la estructura de tamaños (usando como criterio de tamaño el dap) de varias poblaciones de plantas arbóreas representativas de la selva de Los Tuxtlas (Martínez-Ramos y Álvarez-Buylla, datos no publicados). Especies como Croton schedianus, Brosimum alicastrum, Pseudolmedia oxyphyllaria, son representantes de la estructura tipo I. Especies como Heliocarpus appendiculatus, Stemmadenia donnell-smithii y Turpinia occidentalis, del tipo II y especies como Cecropia obtusifolia, Pterocarpus rohorii y Nectandra ambigens, entre otras, son representantes de la estructura del tipo III. Es interesante que especies que difieren ecológicamente muestran una estructura similar; por ejemplo, árboles como C.obtusifolia, C. schedianus y $H$. appendiculatus demandan ambientes lumínicamente ricos para establecerse y madurar, mientras que $B$. alicastrum, P. oxyphyllaria, G. glabra, N. ambigens y T. occidentalis, cuando son jóvenes, pueden sobrevivir y crecer bajo condiciones de sombra (Martínez-Ramos, 1985). Por lo tanto, la estructura de tamaños parece no ser un criterio importante para distinguir grupos de especies ecológicamente diferentes.

Sin embargo, el cambio en la estructura de tamaños de una población, al variar el ambiente, puede, ayudar a identificar especies con diferencias ecológicas importantes. En Panamá, la estructura de tamaños de poblaciones de árboles fuertemente demandantes de luz es más flexible (es decir cambia de un tipo de estructura a otro) que la de poblaciones de árboles tolerantes a la sombra (Hubbell y Foster, 1987). En Los Tuxtlas, los árboles pioneros cambian de una estructura tipo-I, en sitios recién perturbados, a una de tipo II en sitios sucesionales con el dosel cerrado (Sarukhán et al., 1985) mientras que el árbol tolerante a la sombra Pseudolmedia oxyphyllaria tiende a mantener una estructura tipo-I a través de todo el mosaico de regeneración.

Sin embargo, en Los Tuxtlas también se ha observado que la variación en la estructura poblacional de plantas tolerantes a la sombra no es despreciable. La planta herbácea del sotobosque Aphelandra aurantiaca (Acanthaceae) muestra una estructura tipo-I en los claros, donde ocurre un activo reclutamiento de plántulas, una de tipo-III en hábitats sucesionales y una de tipo-II en hábitats de bosque maduro, donde el reclutamiento de plántulas es pobre (Calvo, 1989). La estructura poblacional de Astrocaryum mexicanum varía entre los tipos I y III a través del mosaico de regeneración (Sarukhán et al., 1985). Considerando estos casos para plantas tolerantes a la sombra puede decirse, en general, que la estructura de tamaños de una población expresa: 1) la sensibilidad de las plantas a cambios en factores ambientales críticos para el reclutamiento, la sobrevivencia y desarrollo de los individuos y 2) la intensidad y frecuencia con que varían estos factores a través del espacio y del tiempo. 

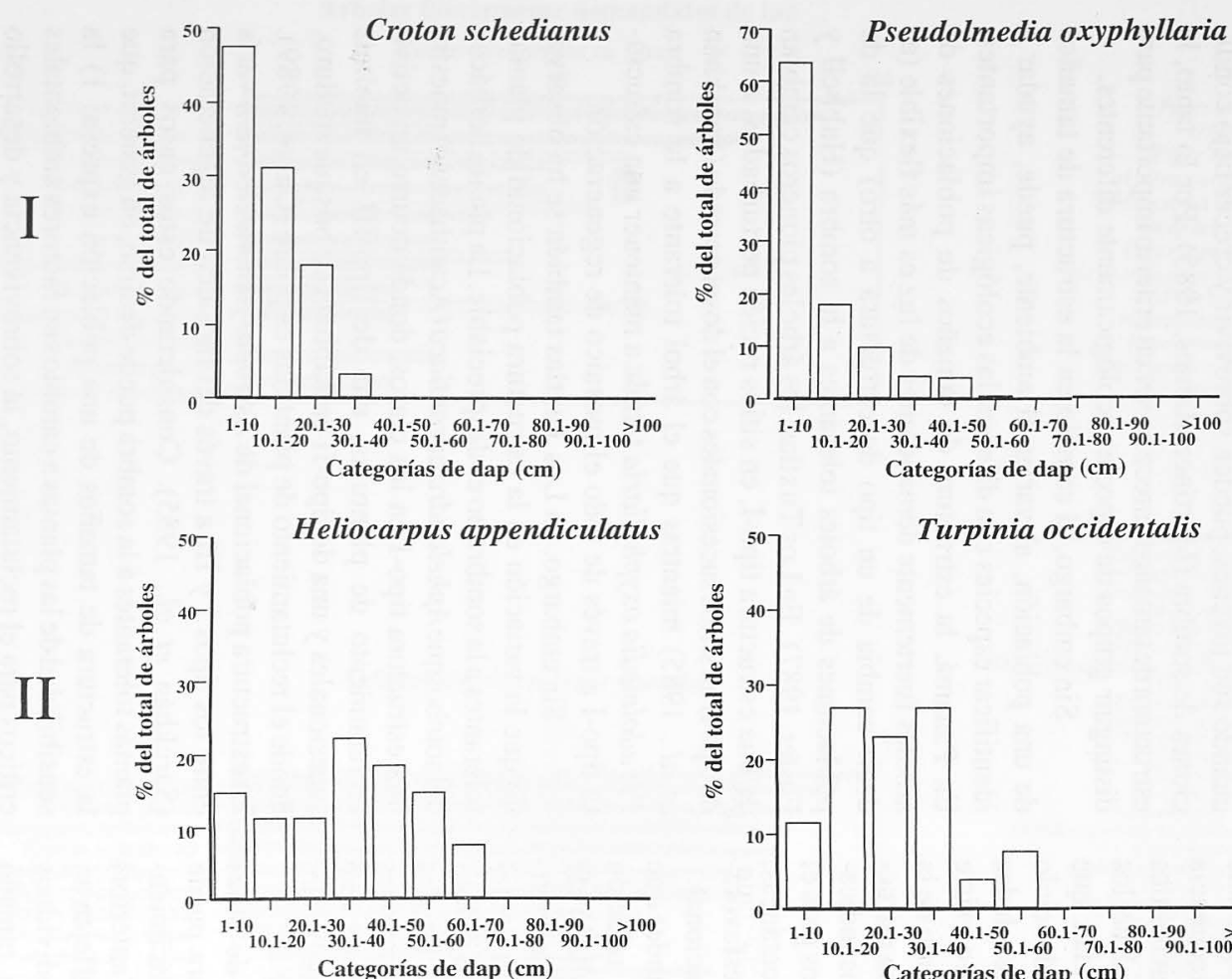

Categorías de dap $(\mathrm{cm})$

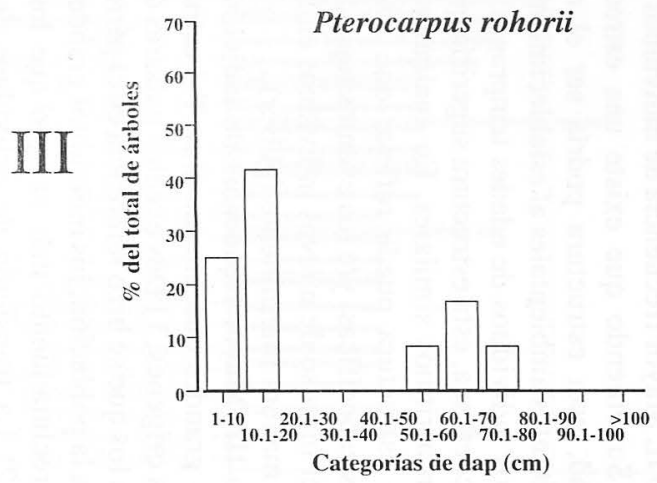

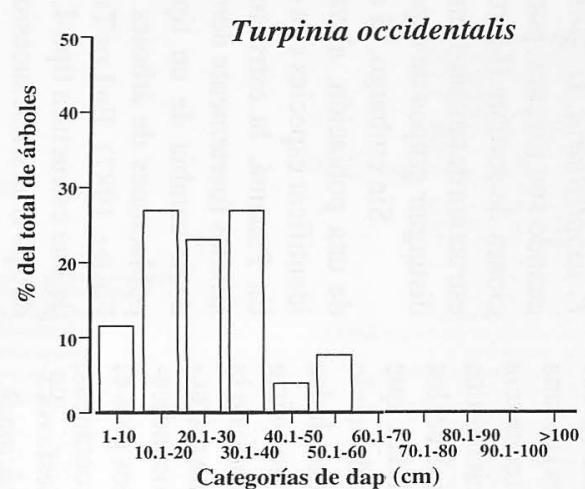

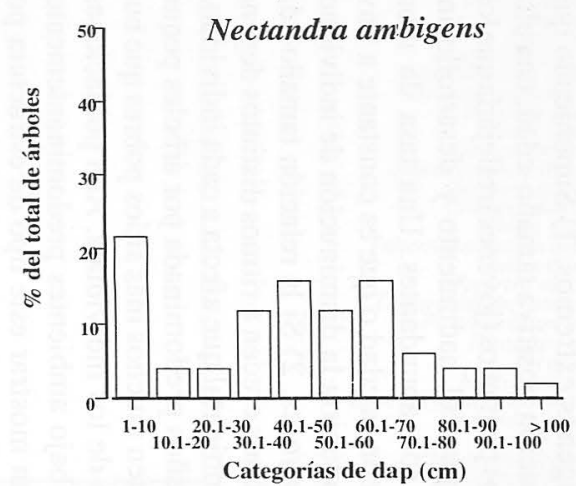

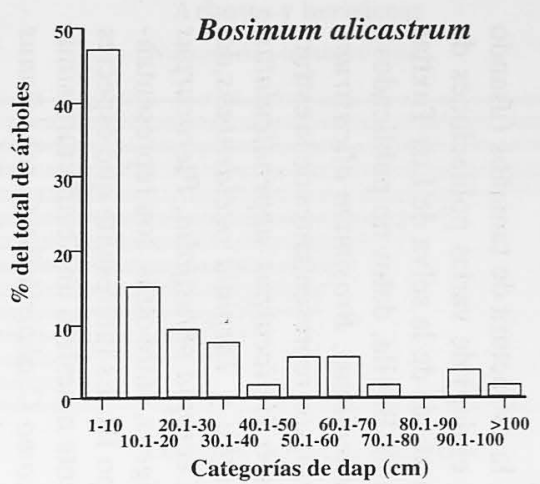
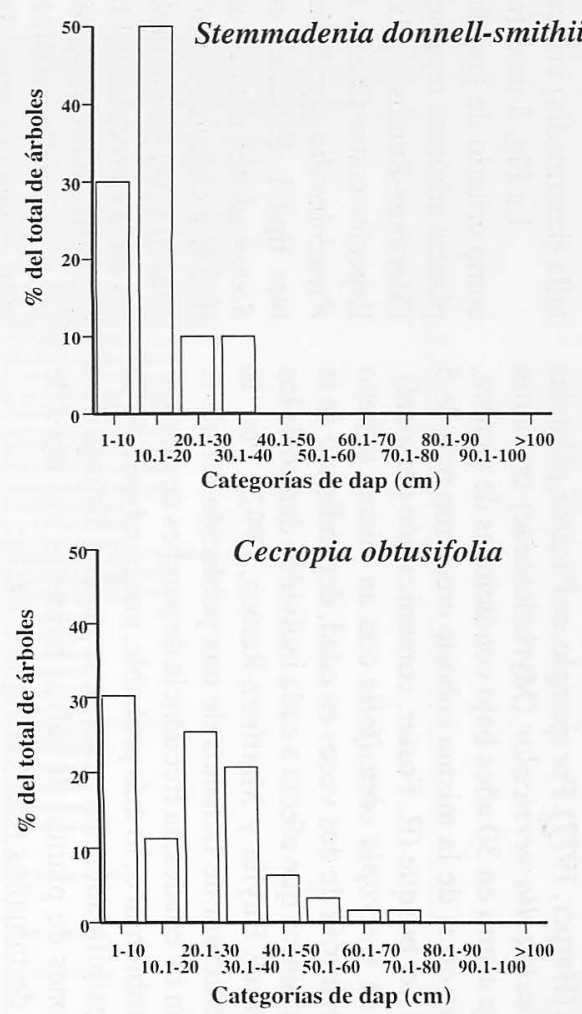


\section{Tablas de vida}

En las selvas húmedas, prácticamente todas las poblaciones de plantas presentan generaciones sobrepuestas (Begon et al., 1986). La densidad y la estructura de estas poblaciones resultan de balances dinámicos entre el nacimiento y la sobrevivencia de individuos de diferente edad que simultáneamente concurren.

\section{Sobrevivencia}

En las poblaciones que dependen de la reproducción sexual como único medio de propagación, generalmente la probabilidad que tiene una planta de morir varía con su edad y/ o vigor (Harper, 1977). Las semillas, plántulas y plantas juveniles sufren las tasas de mortalidad más elevadas (ÁlvarezBuylla y Martínez-Ramos, 1992; Clark, 1994). En poblaciones que se propagan a través de retoños vegetativos, como sucede con la planta herbácea Aphelandra aurantiaca, la probabilidad de muerte es prácticamente constante a través del ciclo de vida de los retoños (Calvo, 1989).

La Fig. 4 muestra curvas de sobrevivencia de las poblaciones de árboles tropicales que se han estudiado en México (Álvarez-Buylla y Martínez-Ramos, 1992). Las curvas se obtuvieron de varias fuentes y siguiendo la metodología descrita por Sarukhán (1980). Independientemente de las especies, estas poblaciones se caracterizan por elevadas tasas de mortalidad durante los primeros años de vida y elevadas tasas de sobrevivencia a edades avanzadas. En las palmas Astrocaryum mexicanum y Chamaedorea alternas (antes tepejilote), y en el árbol Cecropia obtusifolia, la mortalidad tiende a aumentar hacia el final del ciclo de vida, lo cual posiblemente refleja una etapa senil.

Patrones similares a los anteriores surgen cuando se utiliza el tamaño más que la edad como descriptor del estado de desarrollo de los individuos (Hubbell y Foster, 1990a). En poblaciones de árboles fuertemente demandantes de luz, la tasa de mortalidad es muy elevada en los individuos de tallas pequeñas y disminuye a medida que los árboles alcanzan tallas mayores. En Los Tuxtlas, un ejemplo típico es aquel de Cecropia obtusifolia (cf. Fig. 4). Las especies que pueden desarrollarse en la sombra muestran mayores tasas de sobrevivencia en todo su ámbito de tamaños (Hubbell y Foster, 1990a), como es el caso de la mayoría de las especies arbóreas mostradas en la Fig. 4.

En las poblaciones de árboles hasta ahora estudiadas, la esperanza de vida futura (número de años que restan de vida a un individuo a partir de una cierta edad) aumenta a un máximo y posteriormente decae (Fig. 5). En general, la máxima esperanza de vida coincide con la edad en la que se inicia la etapa reproductiva de estas plantas (Sarukhán, 1980; Álvarez-Buylla y Martínez-Ramos, 1992). El aumento inicial en esperanza de vida puede deberse a que el riesgo de muerte tiende a disminuir a medida que los árboles crecen en altura y alcanzan mejores niveles de recursos lumínicos (Sarukhán, 1980). Omphalea oleifera y Cecropia obtusifolia parecen ser buenos ejemplos de esta idea (Fig. 5), ya que en estos árboles la máxima esperanza de vida ocurre cuando la copa llega al dosel superior de la selva (aproximadamente a los $20 \mathrm{~m}$ de altura) y queda libre de cualquier interferencia lumínica.

Al alcanzar la etapa reproductiva, la tasa de muerte de los árboles disminuye a un valor mínimo y la esperanza de vida se acorta en función de la longevidad máxima. Existe un ámbito amplio de longevidad entre los árboles de la selva de Los Tuxtlas que varía desde menos de ocho años, como es el caso de Carica papaya (Caricaceae) y Cnidosculus multilobus (Euphorbiaceae), hasta más de 200 años en muchos árboles del sotobosque y del dosel de la selva (Lieberman et al., 1985a; Sarukhán et al., 1985). Se han explorado las fuentes de mortalidad que afectan a las poblaciones de plantas de las selvas húmedas a través del ciclo de vida. Algunas de estas fuentes se resumen a continuación.

\section{1) Estadio de semilla}

La muerte de una semilla puede ocurrir cuando aún se encuentra unida a la planta materna, antes de ser dispersada (por ejemplo, mortalidad pre-dispersión), o cuando ingresa al suelo, después de ser dispersada (por ejemplo, mortalidad post-dispersión). La probabilidad de muerte en estas dos etapas suele ser alta, pero su ámbito de variación entre especies es amplio (Janzen, 1969, 1971; Sarukhán, 1978; Dirzo y Domínguez, 1986). Por ejemplo, más del $95 \%$ de las semillas que produce un individuo de Astrocaryum mexicanum son removidas por mamíferos; cerca del $45 \%$ se remueve antes de la dispersión y el resto en el suelo (Sarukhán, 1978, 1980; Rodríguez-Velázquez, 1994). Por el contrario, más del $75 \%$ de la cosecha de semillas del árbol Omphalea oleifera escapan a la depredación y llegan al estadio de plántula (Palomeque, 1988).

La muerte de las semillas es causada por factores de tipo físico (Vázquez-Yanes y Orozco-Segovia, 1984, 1993), pero sobre todo de tipo biótico (Janzen, 1969, 1970; Dirzo, 1984, 1987; Schupp, 1988a, b; Horvitz y Schemske, 1994). Existen tres grupos de depredadores de semillas principales: los microorganismos patógenos, los insectos y los vertebrados (aves y mamíferos). El riesgo de muerte por depredación depende de la efectividad de las estructuras (físicas y/o químicas) de las semillas que actúan como defensas contra los depredadores, de la conducta de ataque de los depredadores y de la manera en que las plantas despliegan sus frutos y semillas (Janzen, 1969; Dirzo, 1987). El riesgo de depredación per capita tiende a disminuir si las plantas producen semillas en tiempos cortos y de manera sincronizada con el resto de la población; en cambio, tiende a aumentar cuando una cosecha de semillas se produce asincrónicamente, repartida a través de un largo periodo de fructificación (Janzen, 1976, 1978).

La probabilidad de depredación también tiende a disminuir en las poblaciones que muestran fluctuaciones fuertes e irregulares en la producción de semillas (Janzen, 


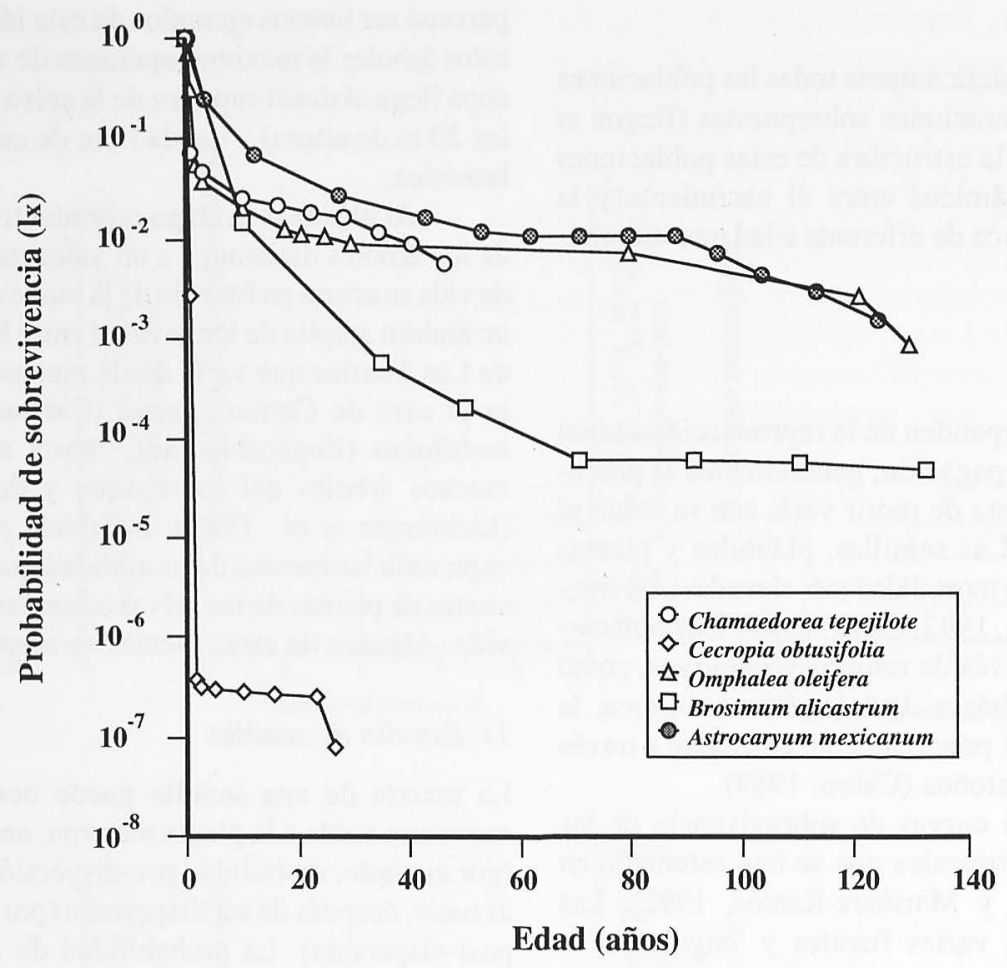

Figura 4. Curvas de sobrevivencia a edades específicas (lx) para varias poblaciones de árboles de selvas húmedas de México. Modificado de Álvarez-Buylla y Martínez-Ramos (1992). Note escala logarítmica en el eje de las Y's.

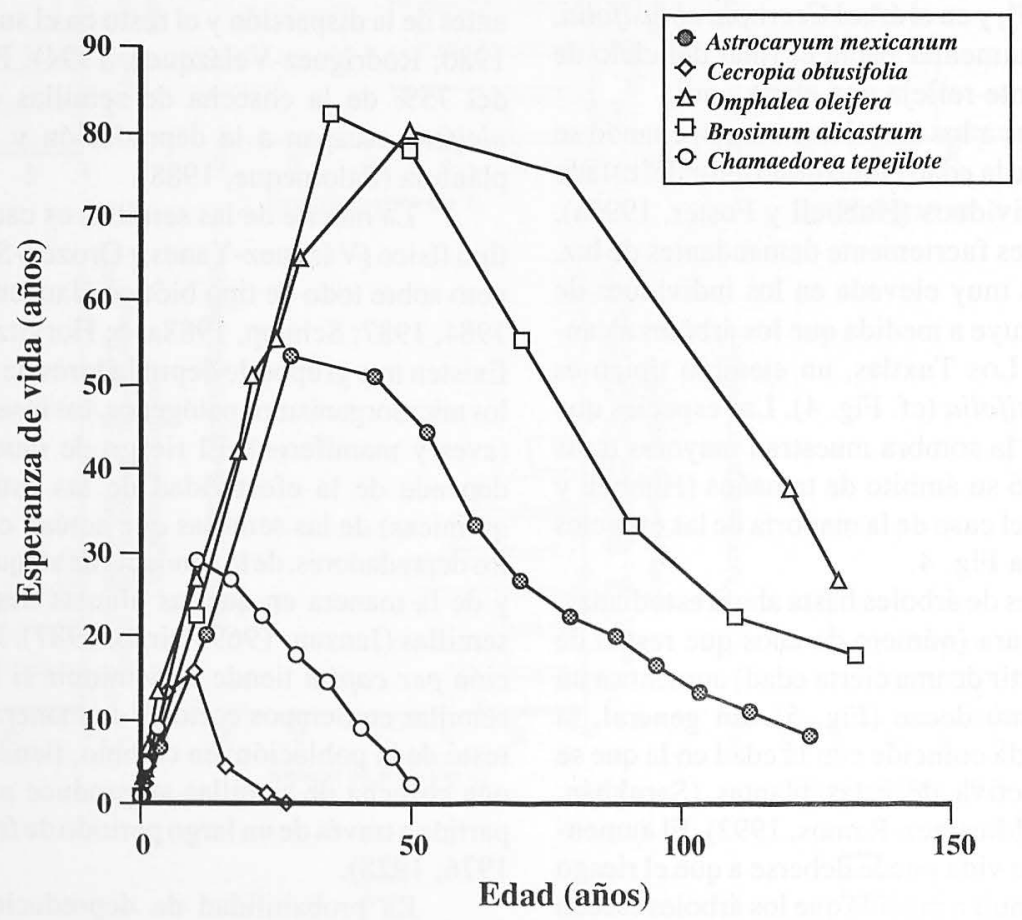

Figura 5. Curvas de esperanza de vida a edades específicas (ex) para varias poblaciones de árboles de selvas húmedas de México (modificado de Álvarez-Buylla y Martínez-Ramos, 1992). 
1976; 1978; Silvertown, 1980). Cuando el ataque de los depredadores se acentúa con el grado de agregación de las semillas, los agentes que las dispersan juegan un papel importante en la sobrevivencia de las mismas (Clark y Clark, 1984; Schupp 1988a, b). Se ha observado que la probabilidad de remoción de semillas varía entre las fases del mosaico de regeneración, presumiblemente porque la conducta de búsqueda o ataque de los depredadores se modifica entre estas fases (Samper, 1992; Schupp, 1988a, b; Schupp y Frost, 1989; Rodríguez-Velázquez, 1994). Por último, se ha propuesto que la probabilidad de depredación se relaciona de manera positiva con el tiempo que tardan las semillas en germinar, es decir, el tiempo que quedan expuestas al ataque de los depredadores (Garwood, 1983; Samper, 1992). Sin embargo, en Los Tuxtlas se ha observado que semillas que tardan hasta nueve meses en germinar, tienen un bajo riesgo de muerte al quedar sepultadas por la abundante hojarasca que cae al piso de la selva (Rodríguez-Velázquez, 1994).

\section{2) Estadios de plántula y juvenil}

En muchas poblaciones de plantas de larga vida, las plántulas e individuos jóvenes se desarrollan, al menos durante algún tiempo, en condiciones limitantes de recursos lumínicos, creciendo, si acaso, a ritmos lentos (Popma y Bongers, 1988). Estas plantas aceleran su crecimiento cuando aumenta la energía lumínica en el sitio, debido a la formación de un claro en el dosel (Augspurger, 1984a; Clark y Clark, 1987a, b; Popma y Bongers, 1988, 1991; Bongers y Popma, 1990). El recambio de hojas en la copa de estas plantas es muy lento en condiciones de penumbra, de manera que una hoja puede vivir funcionalmente activa por períodos mayores a un año (Meave del Castillo, 1987; Bongers, Popma e Iriarte, 1988; Bongers y Popma, 1990). No obstante su prolongada exposición a herbívoros, las hojas de estas plantas muestran, en general, bajos niveles de defoliación $(<10 \%)$, presumiblemente porque poseen defensas químicas que las protegen del ataque de estos animales (Coley, 1983; Coley et al., 1985; Dirzo, 1987; De la Cruz y Dirzo, 1988).

Una proporción importante de las muertes que ocurren durante los primeros estadios de vida de las plantas se debe a factores físicos, tales como la pérdida de follaje o la ruptura del tallo y meristemos por la caída de ramas (Clark y Clark, 1989, 1991; Aide, 1987; Howe, 1990a, b; Molofski y Augspurger, 1992). Se ha mostrado experimentalmente que la defoliación aumenta en forma significativa la probabilidad de muertes de las plántulas y plantas juveniles (Mendoza, 1987; Dirzo, 1984; Careaga, 1989; Oyama y Mendoza, 1990). La hojarasca que cae sobre las plántulas puede ocasionar su muerte o bien favorecer su sobrevivencia, dependiendo de la especie en cuestión. Las plántulas de tamaño pequeño, que poseen cotiledones fotosintéticos, tienden a morir al quedar sepultadas por la hojarasca (Vázquez-Yanes et al., 1991). Las plántulas que elongan epicótilos largos, ubicando las hojas muy por arriba del nivel del suelo, y que poseen gran cantidad de reservas cotiledonarias, difí- cilmente son sepultadas por la hojarasca. Para estas plántulas grandes, la acumulación de hojarasca puede crear situaciones microambientales (por ejemplo, de humedad y de nutrimentos) que favorecen el crecimiento de las plántulas (Molofski y Augspurger, 1992; Samper, 1992). En Manaus, Brasil, la hojarasca protege a las plántulas del árbol Micropholis venulosa (Sapotaceae) del ataque de larvas de palomillas; el riesgo de muerte de estas plántulas aumenta si se encuentran libres de hojarasca (Benítez, 1995).

Otras fuentes de mortalidad surgen de los daños producidos por animales herbívoros, tanto insectos como mamíferos (Clark y Clark, 1985; Dirzo, 1987b; Howe, 1990a; Terborgh et al., 1993), y/o microorganismos patógenos (Augspurger, 1984b; Augspurger y Kelly, 1984). En Los Tuxtlas, las raíces de individuos jóvenes de Astrocaryum mexicanum y de Chamaedorea alternans son roídas por tuzas de Orthogeomys hyspidus (Geomidae), causándoles la muerte (observaciones personales). La sobrevivencia de plántulas de Omphalea oleifera en la sombra se correlacionó negativamente con el grado de herbivoría provocado por las larvas de la palomilla Urania fulgens (Palomeque, 1988). Experimentalmente, se ha demostrado que las plántulas que sufren altos niveles de defoliación, o que sufren daños severos por hongos, mueren si las plántulas crecen en agregados y bajo niveles reducidos de luz (Augspurger, 1984b; Augspurger y Kelly, 1984; Dirzo, 1984). Sin embargo, bajo altos niveles de energía lumínica las plántulas pueden sobrevivir a estos daños (Dirzo, 1984; Augspurger, 1984b). La agregación de individuos puede favorecer el contagio de microorganismos patógenos. En la isla de Barro Colorado, Panamá, se observó que la agregación entre individuos juveniles y adultos de la especies arbórea Ocotea whiteii propicia el contagio de un patógeno que provoca úlceras en el tronco y la muerte de los juveniles (Gilbert et al., 1994).

La tasa de sobrevivencia de plántulas bajo condiciones de sombra varía notablemente entre especies. Por ejemplo, en Los Tuxtlas se registró para las plántulas de 40 especies arbóreas una tasa promedio anual de muerte de 0.50 ind ind $^{-1}$ año $^{-1}$ (e.e. $=0.042 ; \mathrm{CV}=56.5 \%$ ), con un ámbito de variación entre especies de cero hasta 1.00 (Fig. 6a). Esta variación se relacionó positivamente con la variación interespecífica en el tamaño de las semillas (MartínezRamos, 1994). Si el tamaño de la semilla es un supuesto indicador de los recursos maternos por plántula (Fenner, 1985), esta relación pudo deberse a que, bajo sombra, la sobrevivencia de las plántulas depende de la cantidad y calidad de recursos maternos con que disponen en los cotiledones y/o el epicótilo (sin embargo, ver Augspurger, 1986; Kitajima, 1994). Diferencias en la habilidad de las plántulas para mantener un balance positivo de carbono en la sombra (Chazdon, 1988; Popma y Bongers, 1988) también pudieron originar la variación interespecífica observada en la sobrevivencia de las plántulas (Martínez-Ramos, 1994).

Al transitar las plántulas al estadio juvenil la probabilidad de muerte se reduce, ya sea porque los daños físicos y bióticos disminuyen en intensidad, porque la capacidad de 

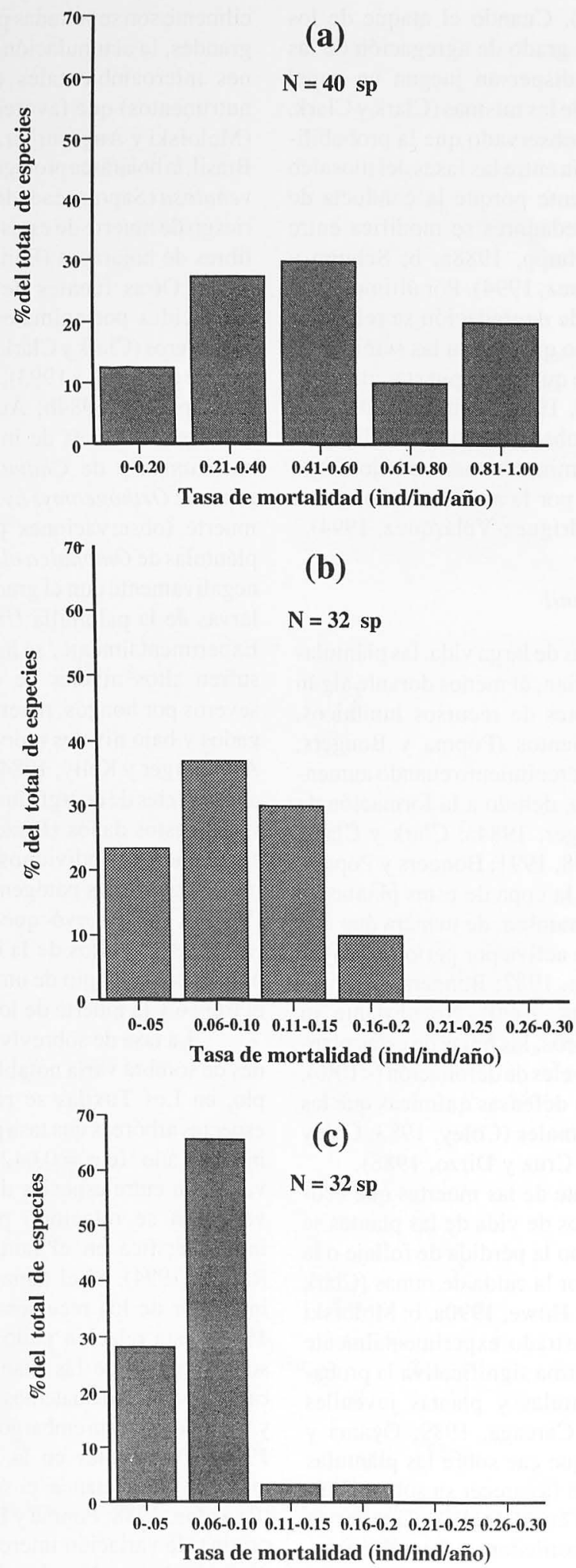

Figura 6. Variación en las tasas de mortalidad anual $\left(\mathrm{q}_{\mathrm{x}}\right)$ a nivel de la comunidad de árboles de la selva de Los Tuxtlas: a) poblaciones de plántulas recién nacidas bajo condiciones de sombra (modificado de Martínez-Ramos, 1991), b) poblaciones de árboles juveniles (1-5 cm en dap) y c) poblaciones de árboles adultos ( $\geq 10 \mathrm{~cm}$ en dap) (M. Martínez-Ramos, T. Hernández y E. Álvarez-Buylla, datos no publicados). 
las plantas juveniles para contrarrestar tales daños es mayor o bien debido a ambas posibilidades. En un grupo de 32 poblaciones de diferentes especies arbóreas de la selva de Los Tuxtlas, se estimó una tasa promedio anual de muerte de 0.051 ind ind $^{-1}$ año $^{-1}($ e.e. $=0.007)$ para árboles juveniles de 1 a $5 \mathrm{~cm}$ de dap. Esta probabilidad es diez veces menor que la registrada en el estadio de plántula para las mismas especies (Fig. 6a y 6b). También el nivel de variación interespecífica en la tasa de mortalidad de árboles juveniles es mayor (coeficiente de variación $=79.7 \%$ ) que el observado en la comunidad de plántulas.

La existencia de tasas de mortalidad muy elevadas en las poblaciones de plantas heliófilas sugiere que la colonización de sitios abiertos es un proceso difícil; por ejemplo, sólo cerca de cuatro de cada 10 millones de semillas producidas en un año por un árbol de Cecropia obtusifolia logran germinar y sobrevivir al año de edad (Cuadro 1). Deficiencias lumínicas dentro del claro, deshidratación por excesivas cargas calóricas, el movimiento del sustrato de establecimiento y la pérdida de follaje por daños físicos y/o por herbívoros, son algunas de las causas de mortalidad detectadas en los primeros estadios del ciclo de vida en estas poblaciones de árboles (Coley, 1983; Martínez-Ramos y Álvarez-Buylla, 1986, 1992; Brokaw, 1987; Dirzo, 1987; Nuñez-Farfán y Dirzo, 1988; Álvarez-Buylla y MartínezRamos, 1992).

\section{3) Estadio adulto}

La etapa adulta es el estadio del ciclo de vida de menor riesgo de muerte en las poblaciones de plantas de selvas húmedas. La Fig. 6c muestra valores de la tasa anual de mortalidad de árboles adultos (dap $\geq 10 \mathrm{~cm}$ ) obtenidos para un grupo de especies arbóreas representativas de la selva de Los Tuxtlas. En promedio, para estos árboles se estimó una tasa anual de mortalidad de 0.018 ind ind $^{-1}$ año ${ }^{-1}$ (e.e. $\left.=0.004\right)$. Aunque esta tasa fue 28 y 2.8 veces menor que la obtenida para las plántulas y los árboles juveniles, respectivamente, la variación de la tasa de mortalidad entre especies $(\mathrm{CV}=138.3 \%)$ fue 2.4 y 1.7 veces mayor, respectivamente. Es posible que el aumento de tal variación refleja que las especies tienden a diferenciarse ecológicamente en mayor grado a medida que los árboles avanzan en su ciclo de vida.

Aún no existe la información suficiente para detectar las fuentes de mortalidad más importantes en las poblaciones de plantas adultas. En Los Tuxtlas, alrededor del 1\% de la población de palmas maduras ( $>1 \mathrm{~m}$ de altura del tallo) de Astrocaryum mexicanum son golpeadas o dobladas anualmente por la caída de ramas y árboles (Martínez-Ramos et al., 1988b). Cada año, alrededor de un $4 \%$ de las palmas golpeadas muere debido a que queda destruido el único meristemo de crecimiento apical, o bien porque se daña severamente el sistema de raíces y/o el tejido fotosintético (Martínez-Ramos et al., 1988b). Se ha encontrado que la caída de objetos del dosel es también una fuente de mortalidad importante de las plantas adultas de la planta herbácea
Aphelandra aurantiaca (Calvo, 1989). La presencia de tejidos de alta resistencia en los tallos, así como la posibilidad de clonación de algunas de estas plantas (Calvo, 1989; De Stevens, 1989), parecen ser respuestas adaptativas a la elevada frecuencia de caída de objetos del dosel.

En Astrocaryum mexicanum se encontró que las palmas adultas que poseen copas significativamente más pequeñas que el promedio de la población tienen una mayor probabilidad de morir (Piñero et al., 1984). Es posible que una área foliar reducida resulte de alguna enfermedad que afecta negativamente la capacidad de las palmas para captar luz y nutrirse. En los árboles adultos de Omphalea oleifera se han observado niveles de herbivoría (producidos por larvas de la palomilla Urania fulgens) cercanos al 100\% (Dirzo, 1987; Palomeque, 1988). Sin embargo, un estudio demográfico no detectó que este daño fuese un factor importante para la sobrevivencia y el crecimiento de los árboles a corto plazo (Palomeque, 1988). Las tuzas matan individuos adultos de Chamaedorea alternans pero se desconoce el porcentaje de depredación ocasionado.

En regiones centroamericanas, africanas y asiáticas, se encontró que entre el $1 \%$ y el $4 \%$ de las poblaciones de árboles adultos muere cada año (Lieberman et al., 1985b; Clark, 1994). Estos estudios indican que la muerte de los árboles adultos puede ocurrir por la acción conjunta o única de i) descargas eléctricas, ii) derrumbamiento mecánico, ocasionado por vientos y cargas de peso excesivas (debidas, por ejemplo, a la lluvia y/o a plantas epífitas y lianas), iii) daño severo de herbívoros (tanto vertebrados, por ejemplo elefantes, como invertebrados, principalmente insectos) y parásitos (por ejemplo, nematodos fitófagos de las raíces) (Whitmore, 1982; Lieberman et al., 1985b).

\section{Reproducción}

La capacidad reproductiva de las plantas se expresa con dos parámetros demográficos: la fertilidad y la fecundidad. La fertilidad se refiere al número de gametos sexuales (polen u óvulos) que produce una planta de una edad o tamaño específico por unidad de tiempo. Si consideramos que cada óvulo representa un individuo que potencialmente puede integrarse a la población, entonces la diferencia entre la tasa de fertilidad y la de fecundidad puede representar una transición numéricamente importante en el ciclo de vida de una población. Existe gran variación (desde prácticamente $0 \%$ hasta cerca del $100 \%$ ), tanto dentro como entre poblaciones de diferentes especies, en el éxito con que se lleva a cabo esta transición (Córdova, 1985).

La transición óvulo-semilla está determinada por factores tanto intrínsecos (por ejemplo, mecanismos fisiológicos que permiten la unión de gametos femeninas y masculinas y la maduración de las semillas) como extrínsecos a las plantas (por ejemplo, la disponibilidad de agentes de polinización, herbívoros de flores). En Aphelandra aurantiaca la producción de semillas por planta es menor en los sitios sombreados que en los claros de la selva, aunque la fertilidad 
no difiere entre estos sitios (Calvo, 1989). Un estudio experimental mostró que la diferencia en la producción de semillas se debe a que, en la sombra, una mayor proporción de las flores (y óvulos) que produce una planta son eliminadas por larvas de insectos (Islas, 1995). Si bien existen estudios que han tratado de explicar los valores de la proporción semillas/óvulos en términos de la biología floral de las especies (Bawa, 1979; Bullock y Bawa, 1981; Bullock et al., 1983; Búrquez et al., 1987), la importancia de esta transición para la dinámica de las poblaciones aún queda por averiguarse (Sarukhán, 1978, 1980).

Prácticamente todos las poblaciones de árboles de selvas húmedas son de reproducción policárpica (equivalente al término iteróparo en animales), es decir, los individuos tienen varios eventos reproductivos a lo largo del ciclo de vida. Un caso excepcional es el de Tachigalia versicolor, árbol del dosel superior en selvas de Centro y Sur de América, cuya reproducción es de tipo mocárpico (equivalente al término semelparo en animales), es decir, muere después de tener su único evento reproductivo (Foster, 1977). En la mayoría de las poblaciones de plantas de selva húmeda estudiadas, la natalidad es un proceso que incluye la producción de semillas y la posterior emergencia de las plántulas. En algunas, la producción de propágulos vegetativos, que adquieren independencia fisiológica de la planta materna, representa una fuente importante de natalidad. Por ejemplo, en Los Tuxtlas los nacimientos por vía vegetativa son importantes para las poblaciones de la liana Ipomoea phyllomega (Convolvulaceae; Peñaloza, 1985) y de Aphelandra aurantiaca (Calvo, 1989).

En la Fig. 7 se muestran curvas de fecundidad a edades específicas obtenidas para varias poblaciones de árboles. Es importante resaltar la diferencia con la que ocurre la edad a la primera reproducción entre estas poblaciones (ámbito de 3 a 45 años) y los tres tipos de relación fecundidad-edad observables: i) un aumento geométrico de la fecundidad con la edad, como ocurre en Cecropia obtusifolia y en Brosimum alicastrum (Moraceae), ii) un aumento asintótico de la fecundidad hacia un valor constante, como ocurre en Astrocaryum mexicanum y Omphalea oleifera y iii) un aumento hasta un máximo y un decaimiento posterior, como ocurre en Chamaedorea alternans. Éstos son algunos de los

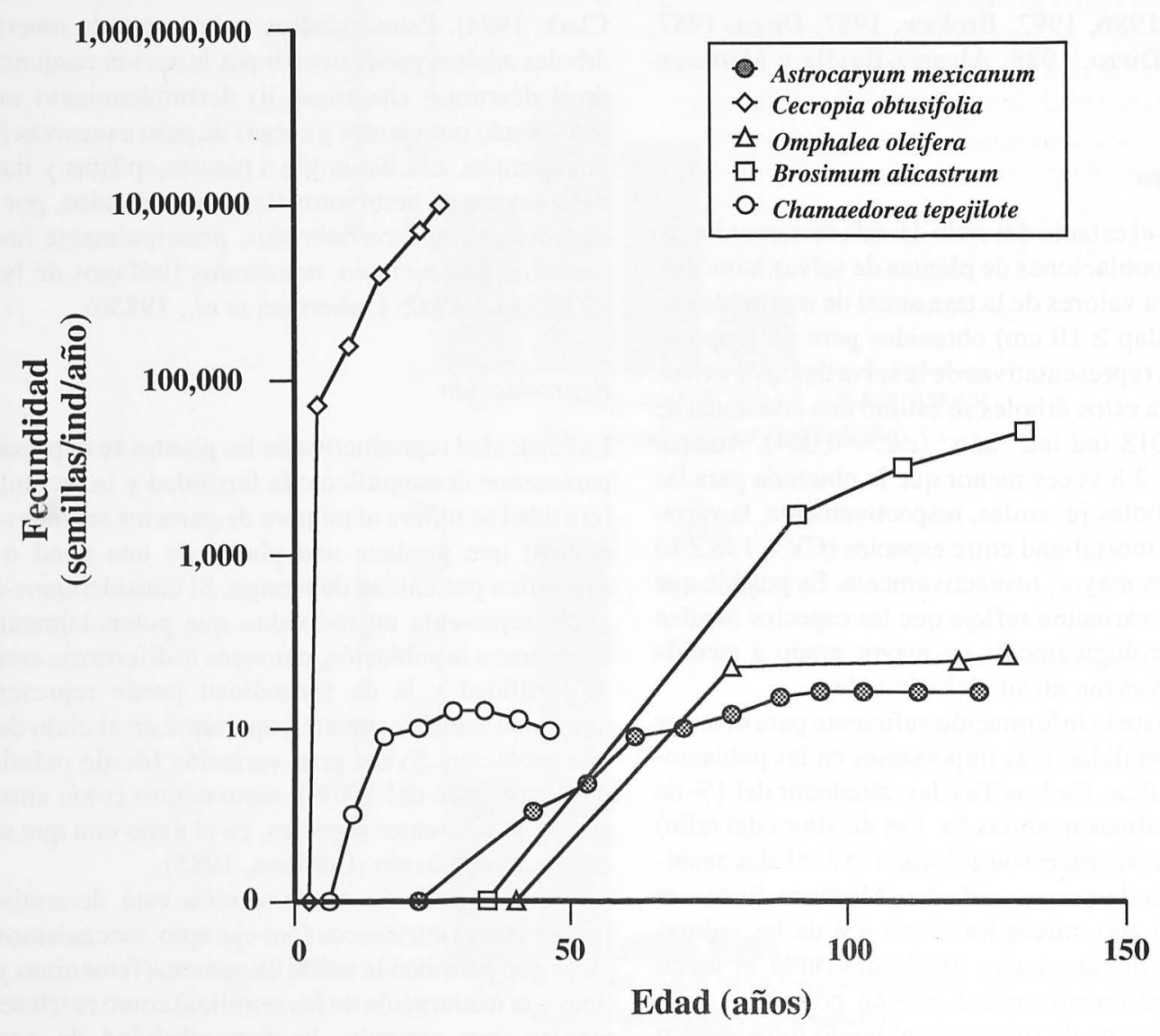

FIgURA 7. Curvas de fecundidad a edades específicas $\left(\mathrm{m}_{\mathrm{x}}\right.$ ) para varias poblaciones de árboles de selvas húmedas de México (modificado de ÁlvarezBuylla y Martínez-Ramos, 1992). 
varios patrones de fecundidad-edad (tamaño) que pueden observarse en las poblaciones de plantas (Silvertown, 1982).

La capacidad de una planta para producir semillas o retoños vegetativos depende de los recursos y la energía que capturan, almacenan y destinan al proceso de la reproducción. Por lo tanto, no es raro encontrar que el número de semillas por cosecha se relacione con variables asociadas con el tamaño de las plantas (tales como el área fotosintética, el tamaño de raíces y rizomas, o de estructuras de almacenamiento en tallos o troncos) más que con su edad (Clauss y Aarssen, 1994). En Cecropia obtusifolia la fecundidad aumenta potencialmentecon el área foliar total de la copa, pasando de cien mil semillas por año, cuando el árbol tiene tres años y la copa mide en promedio $10 \mathrm{~m}^{2}$ de área foliar, a cerca de diez millones de semillas por año, cuando tiene 30 años y cerca de $100 \mathrm{~m}^{2}$ de área foliar (Álvarez-Buylla y Martínez-Ramos, 1992). Este árbol logra una extraordinaria capacidad reproductiva exponiendo siempre sus hojas a la luz solar directa, evitando la sobreposición entre las hojas y manteniendo elevadas tasas de fijación de carbono (Ackerly, 1993). Así, si bien la fecundidad de Cecropia obtusifolia aumenta dos órdenes de magnitud a través de su fase reproductiva (Fig. 7), la eficiencia de producción de semillas por unidad de área foliar se mantiene aproximadamente constante ( $\mathrm{ca}$. 10,000 semillas $\mathrm{m}^{-2}$ año-1 $)$. Es probable que la muerte relativamente rápida de estos árboles ( $<40$ años) se deba a que, para mantener esta eficiencia, sacrifican energía necesaria para mantener los tejidos no fotosintéticos (por ejemplo, troncos, ramas y raíces) y cuya demanda también va en aumento con el desarrollo del árbol.

En la palma tolerante a la sombra Astrocaryum mexicanum la relación entre fecundidad y área fotosintética es diferente. El primer evento reproductivo ocurre cuando la palma alcanza $1 \mathrm{~m}$ de altura ( $c a ., 25$ años de edad) y una copa compuesta por 12 frondas, que en total miden $5.5 \mathrm{~m}^{2}$ en área foliar. Este primer evento produce, en promedio, 2.2 frutos grandes (3-5 cm de diámetro) unisemillados. Cuando la palma tiene $7 \mathrm{~m}$ de altura ( $c a .125$ años de edad) y un área foliar total de $10.5 \mathrm{~m}^{2}$ la fecundidad aumenta a 25 frutos por año (Piñero et al., 1994). La fecundidad aumenta porque la eficiencia de producción de semillas por unidad de área fotosintética aumenta con la altura ganada, pasando de un valor inicial de 0.4 a uno final de 2.4 frutos $\mathrm{m}^{-2}$ año $^{-1}$. Esta eficiencia se multiplica seis veces a lo largo del ciclo de vida aunque el área foliar sólo se duplica. En parte, esto se debe a que en el ambiente umbrío del sotobosque ganancias en altura exponen a las hojas a mayores niveles de calidad y cantidad de recursos lumínicos (Pérez-Ishiwara, 1990). Esta idea es apoyada por el hecho de que en los claros las palmas maduran más rápidamente y aumentan al doble su fecundidad que en los sitios sombreados (Martínez-Ramos et al., 1988a).

Causas morfológicas pueden también determinar el tipo de relación fecundidad-edad. Por ejemplo, la ramificación de los árboles puede ser profusa si al ramificarse cada ramilla produce más de una; éste es el caso de Cecropia obtusifolia y Brosimum alicastrum (Álvarez-Buylla y Martínez-Ramos, 1992). Ya que en ambos árboles se producen infrutescencias axilares por cada ramilla formada, es de esperarse que el número de semillas por árbol aumente también profusamente (de manera geométrica) a medida que los árboles se ramifican. Por el contrario, las palmas Astrocaryum mexicanum y Chamaedorea alternans crecen a través de un único meristemo, localizado en el ápice del tallo. Este meristemo produce tanto una hoja como una yema que dará origen a una infrutescencia. Debido a que cada infrutescencia posee un número aproximadamente constante de frutos (Piñero y Sarukhán, 1982; Oyama, 1990), la fecundidad depende en gran medida del número de hojas producido por año. A partir de cierta edad, la producción de hojas (y en consecuencia la fecundidad) se mantiene relativamente constante, por lo que el aumento inicial en fecundidad observada en estas palmas (Fig. 7) puede interpretarse como un proceso de ganancia en energía lumínica a medida que los individuos ganan altura (Sarukhán et al., 1984; Oyama, 1990). Por lo tanto, existe un período durante el cual la fecundidad de estas palmas se encuentra limitada por un factor externo (i.e. la luz) y uno durante el cual la morfología es su principal limitante.

Este tipo de argumentos podrían no ser los únicos en explicar las relaciones fecundidad-edad observadas en las plantas tropicales. Por ejemplo, el árbol Omphalea oleifera se ramifica y produce múltiples meristemos que originan frutos; sin embargo, la relación fecudidad-edad es semejante a la de las palmas que poseen un solo meristemo de crecimiento (Fig. 7).

\section{DINAMICA DE LAS POBLACIONES}

La densidad de una población puede variar a través del tiempo debido a que las tasas de nacimiento y de muerte que operan sobre ella se ven modificadas por factores abióticos (tales como condiciones de temperatura y precipitación), cuya acción generalmente no depende de la densidad de la población, y por factores bióticos (tales como depredadores, competidores y mutualistas), que a menudo actúan dependiendo de la densidad de la misma (Begon et al., 1986). En esta sección discutiremos aspectos de la dinámica de poblaciones de plantas de selvas húmedas, considerando : i) la suposición de que las poblaciones crecen bajo un ambiente homogéneo y temporalmente invariable, ii) el análisis de la dinámica de las poblaciones cuando se considera variación en el ambiente y iii) el efecto de fenómenos dependientes de la densidad sobre la dinámica de las poblaciones.

\section{Crecimiento de poblaciones bajo ambientes homogéneos}

Suponiendo que el ambiente no varía con el tiempo ni espacialmente, el estado dinámico de una población puede analizarse con un modelo simple que considera que las poblaciones tienen el potencial de crecer de manera exponencial 
(Silvertown , 1982). La tasa reproductiva básica (Ro) expresa los cambios demográficos que ocurren a través del ciclo de vida en poblaciones estructuradas en edades. El valor de esta tasa se obtiene como $\mathrm{Ro}=\sum \mathrm{l}_{\mathrm{x}} \mathrm{m}_{\mathrm{x}}$ (Begon et al., 1986). Ro es una expresión del número de descendientes que, en promedio, deja un individuo de una generación a otra. De esta manera si $\mathrm{Ro}=1$, en promedio, cada individuo deja un descendiente y por lo tanto la población se mantiene con la misma densidad. Si Ro $>1$, cada individuo deja más de un descendiente y por lo tanto la densidad de la población aumenta. Por último si Ro $<1$, cada individuo deja menos de un descendiente y la densidad de la población disminuye entre generaciones.

En el Cuadro 1 se muestran tablas de vida de tipo vertical (Begon et al., 1986) y los valores de Ro obtenidas para poblaciones de la palma Astrocaryum mexicanum y el árbol Cecropia obtusifolia en Los Tuxtlas, Veracruz. En la población de Cecropia obtusifolia ocurre un recambio mucho más activo de individuos que en la de Astrocaryum mexicanum; sin embargo, esta última tiene una densidad de individuos adultos ca. 100 mayor que la primera. La densidad de la población de $A$. mexicanum prácticamente se mantendría constante de una generación a otra (Ro 1.0), es decir, cada palma dejaría, en promedio a través de su vida, un solo descendiente. Un árbol de C. obtusifolia, en cambio, dejaría ca. 2.5 descendientes, de modo que durante cada generación la densidad de la población aumentaría en esa proporción.

Para poder comparar la tasa de crecimiento de las poblaciones, debemos tener una idea del tiempo que dura una generación $(\mathrm{G})$; éste se obtiene como $\mathrm{G}=\left(\sum \mathrm{x} \mathrm{l}_{\mathrm{x}} \mathrm{m}_{\mathrm{x}}\right) /$ Ro. Por definición, $G$ indica el tiempo promedio que pasa desde el nacimiento del progenitor hasta el nacimiento de sus descendientes (Begon et al., 1986). El tiempo generacional estimado para Astrocaryum mexicanum es cuatro veces mayor que el estimado para Cecropia obtusifolia (Cuadro 1). Así, mientras que la densidad de la población de la palma permanecería aproximadamente igual después de ocho décadas, la de $C$. obtusifolia crecería 2.5 veces cada dos décadas.

Debido a que las notables diferencias en tiempos generacionales entre las poblaciones, es conveniente tener la tasa de crecimiento expresada en una unidad de tiempo comparable para cualquier población. La tasa instantánea de crecimiento $\mathrm{r}=\ln (\mathrm{Ro}) / \mathrm{G}$ y la tasa finita de crecimiento $\lambda=$ $\mathrm{e}^{\mathrm{r}}$, donde e es la base de los logaritmos naturales (Begon $e t$ al., 1986) son índices útiles al respecto. Si $r=0$ entonces la densidad de la población permanece constante, si $r>0$ la población crece y diminuye si $r<0$. Los valores que toma $\lambda$ tienen el mismo significado para el crecimiento de la población que aquellos de Ro, pero ahora definidos por unidad de tiempo y no por generación. La $\lambda$ estimada para Astrocaryum mexicanum es de 1.0002 (equivalente al $0.02 \%$ de crecimiento por año) y la estimada para Cecropia obtusifolia es de 1.0429 (4.3\% por año).

Existen riesgos al estimar la tasa de crecimiento de una población utilizando tablas de vida de tipo vertical.
Primero, la suposición de que las tasas de fecundidad y sobrevivencia a edades específicas permanecen constantes a través del tiempo es irreal. Los factores ambientales que afectan a estas tasas pueden variar a través del tiempo de manera importante y consecuentemente $\lambda$ puede modificarse. Segundo, ya que el valor de G depende de la exactitud con que se estima la edad de los individuos, estimaciones inexactas provocan pobres estimaciones de $\lambda$. Por ejemplo, en Cecropia obtusifolia el error de estimación de la edad es mayor al 25\% (Álvarez-Buylla y Martínez-Ramos, 1992). Si $\mathrm{G}$ fuese 16.5 años (25\% mayor que el promedio estimado de 22.1 años) $\lambda$ sería 1.058 , mientras que sería 1.034 si $\mathrm{G}$ fuese 27.7 años (25\% menor al promedio). Tal error produciría que el tiempo estimado para la duplicación de la población (ver más adelante) variase entre 12 y 21 años.

Los modelos matriciales de proyección lineal, para poblaciones estructuradas en estadios de desarrollo más que en categorías de edad, son útiles en el análisis de la dinámica de poblaciones cuando la relación edad-tamaño es pobre (Lefkovitch, 1965). En estos modelos las tasas de sobrevivencia y fecundidad estadio-específicas se expresan por unidad de tiempo (comúnmente, un año). Durante una unidad de tiempo una planta que se encuentra en un estadio puede o no producir semillas, puede permanecer en el mismo estadio, avanzar a otro o bien puede regresar a uno anterior anterior. En plantas, es posible que un individuo que perdió parte de sus tejidos por alguna razón (por ejemplo, al ser ramoneada por herbívoros) sea demográficamente equivalente a individuos que poseen su nueva talla y no a aquellos que tienen su talla anterior (Dirzo, 1984).

Un modelo matricial tipo Lefkovitch se conforma de una matriz (A) y un vector (v). A comprende a su vez cuatro partes principales: 1) el primer renglón define los valores de fecundidad $\left(\mathrm{F}_{\mathrm{ij}}\right.$, donde i y $\mathrm{j}$ son las categoría de tamaño o estadio de vida $1,2,3, \ldots, \mathrm{i}$; en este caso $\mathrm{i}=1$ ); 2 ) la diagonal principal define las probabilidades de permanencia $\left(\mathrm{P}_{\mathrm{ij}}\right.$, para toda $\mathrm{i}=\mathrm{j}$ ), es decir, la proporción de individuos de la categoría i que permanecen en el mismo estadio después de una unidad de tiempo; 3 ) las diagonales por debajo de la principal definen las probabilidades de progresión $\left(\mathrm{G}_{\mathrm{ij}}\right.$, para toda $\mathrm{i}<\mathrm{j}$ ), es decir, la proporción de individuos de la categoría i que pasan a una categoría j, y 4), las diagonales por encima de la principal definen las probabilidades de regresión $\left(R_{i j}\right.$, para toda $\mathrm{i}>\mathrm{j}$ ), es decir, la proporción de individuos de la categoría j que regresan a una categoría i (Lefkovitch, 1965). La matriz puede ilustrarse gráficamente a través de los llamados «ciclos de vida diagramáticos» que denotan las rutas demográficas posibles que un individuo promedio de la población puede seguir a través del ciclo de vida (Hubbell y Werner, 1979). El vector $\mathbf{v}$ define el número de individuos de la población encontrados en cada estadio de vida (para detalles ver Caswell, 1989).

Puede demostrarse que la matriz de proyección es equivalente a $\lambda$ y que su valor está definido por el cociente $\mathrm{N}_{t+1 /}$ $\mathrm{N}_{1}$ cuando éste adquiere un valor constante y la estructura de edades permanece estable (Caswell, 1989), es decir, cuando 
CuAdro 1. Tabla de vida vertical para: (A) la palma Astrocaryum mexicanum y (B) el árbol Cecropia obtusifolia en Los Tuxtlas, Veracruz. Los datos de densidad para la palma están referidos a $600 \mathrm{~m}^{2}$ (modificado de Piñero et al., 1984) y para los del árbol para 5-ha (modificado de ÁlvarezBuylla y Martínez-Ramos, 1992). I.E. = intervalo de clase de edad, $x=$ punto medio de cada clase de edad. Ver más detalles en el texto.

(A)

\begin{tabular}{lrrrrrr} 
I.E. (años) & $x$ (años) & $n_{x}$ & $1_{x}$ & $m_{x}$ & $l_{x} m_{x}$ & $x_{x} m_{x}$ \\
\hline $0-1$ & 0.5 & 690 & 1.000 & - & 0.00 & 0.00 \\
$1-6$ & 3.5 & 175 & 0.254 & - & 0.00 & 0.00 \\
$7-17$ & 12.0 & 47 & 0.068 & - & 0.00 & 0.00 \\
$18-37$ & 27.5 & 19 & 0.028 & - & 0.00 & 0.00 \\
$38-48$ & 43.0 & 11 & 0.016 & 0.2 & 0.00 & 0.14 \\
$49-57$ & 53.0 & 8 & 0.012 & 2.2 & 0.03 & 1.35 \\
$58-66$ & 62.0 & 7 & 0.010 & 8.1 & 0.08 & 5.10 \\
$67-74$ & 70.5 & 7 & 0.010 & 10.3 & 0.10 & 7.37 \\
$75-84$ & 79.5 & 7 & 0.010 & 14.9 & 0.15 & 12.03 \\
$85-91$ & 88.0 & 7 & 0.010 & 22.0 & 0.22 & 19.65 \\
$92-99$ & 95.5 & 5 & 0.007 & 26.0 & 0.19 & 18.01 \\
$100-107$ & 103.5 & 3 & 0.004 & 27.0 & 0.12 & 12.16 \\
$108-118$ & 113.0 & 2 & 0.003 & 27.0 & 0.08 & 8.85 \\
$119-129$ & 124.0 & 1 & 0.001 & 27.0 & 0.04 & 4.86
\end{tabular}

$\mathrm{R}_{\mathrm{o}}=1.0136$
$\mathrm{G}=88.3$ años
$\mathrm{r}=0.0002$
$\lambda=1.0002$

(B)

\begin{tabular}{lrrrrrr} 
I.E. (años) & $\mathrm{x}$ (años) & \multicolumn{1}{c}{$\mathrm{n}_{\mathrm{x}}$} & $1_{\mathrm{x}}$ & $\mathrm{mx}$ & $1_{\mathrm{x}} \mathrm{m}_{\mathrm{x}}$ & $\mathrm{xl}_{\mathrm{x}} \mathrm{m}_{\mathrm{x}}$ \\
\hline $0.0-0.2$ & 0.1 & 63926000 & 1.000 & - & 0.00 & 0.00 \\
$0.2-0.5$ & 0.4 & 177800 & 0.003 & - & 0.00 & 0.00 \\
$0.6-1.0$ & 0.8 & 24 & $3.810^{-7}$ & - & 0.00 & 0.00 \\
$1.0-4.0$ & 2.5 & 20 & $3.110^{-7}$ & - & 0.00 & 0.00 \\
$1.0-9.0$ & 5.0 & 19 & $3.010^{-7}$ & - & 0.00 & 0.00 \\
$3.0-17.0$ & 10.0 & 18 & $2.810^{-7}$ & 251188 & 0.07 & 0.71 \\
$7.0-24.0$ & 15.5 & 17 & $2.710^{-7}$ & 1584893 & 0.42 & 6.53 \\
$10.0-36.0$ & 23.0 & 16 & $2.510^{-7}$ & 5000000 & 1.25 & 28.78 \\
$16.0-37.0$ & 26.5 & 5 & $7.810^{-8}$ & 10000000 & 0.78 & 20.73
\end{tabular}

$$
\begin{aligned}
& \mathrm{R}_{\mathrm{o}}=2.53 \\
& \mathrm{G}=22.1 \text { años } \\
& \mathrm{r}=0.0420 \\
& \lambda=1.0429
\end{aligned}
$$

la proporción de individuos en cada estadio de vida no cambia con el tiempo. Ésta es la llamada estructura estable de la población y depende únicamente de los valores iniciales de los parámetros demográficos de la matriz $\mathrm{A}$. Al igual que con una tabla de vida vertical, este análisis supone que las tasas demográficas permanecen constantes a través del tiempo y $\lambda$ no depende de la densidad de la población (Caswell, 1989).

En Los Tuxtlas se ha estudiado, mediante el uso de modelos matriciales, la dinámica de poblaciones de las palmas Astrocaryum mexicanum (Piñero et al., 1984; Martínez-Ramos et al., 1988a) y Chamaedorea alternans (Oyama, 1987), de los árboles Nectandra ambigens (Lauraceae; Córdova, 1985), Cecropia obtusifolia (Moraceae; Álvarez-Buylla, 1994) y Omphalea oleifera (Euphorbiaceae; Palomeque, 1988), y de las plantas herbáceas Calathea microcephala (Maranthaceae; Horvitz y Schemske, 1986) y Aphelandra aurantiaca (Acanthaceae; Calvo, 1989). En Papantla, Veracruz, Peters (1991) estudió la dinámica poblacional del árbol 
del dosel superior ( $>20 \mathrm{~m}$ de altura) Brosimum alicastrum (Moraceae).

La Fig. 8 muestra modelos matriciales, en la forma de ciclos de vida diagramáticos, para poblaciones de tres especies arbóreas con ciclos de vida contrastantes: el árbol pionero Cecropia obtusifolia (Fig. 8a) la palma del sotobosque de larga vida Astrocaryum mexicanum (Fig. 8b) y el árbol del dosel de larga vida Omphalea oleifera (Fig. 8c). Las probabilidades de progresión en las fases juveniles y adultas, así como la fecundidad son claramente mayores en la población de $C$. obtusifolia y tienen sus valores mínimos en la población de A. mexicanum. El recambio de individuos es muy rápido en la población de $C$. obtusifolia, intermedio en el de $O$. oleifera y muy lento en la de $A$. mexicanum, aunque la densidad de las poblacionales de individuos juveniles y adultos aumenta en el sentido contrario (Fig. 8).

La probabilidad de progresión en los estadios de semilla e infantil es extremadamente baja en la población de Cecropia obtusifolia. En estos estadios de vida, los individuos se ven sometidos a la máxima probabilidad de muerte

\section{(a)}

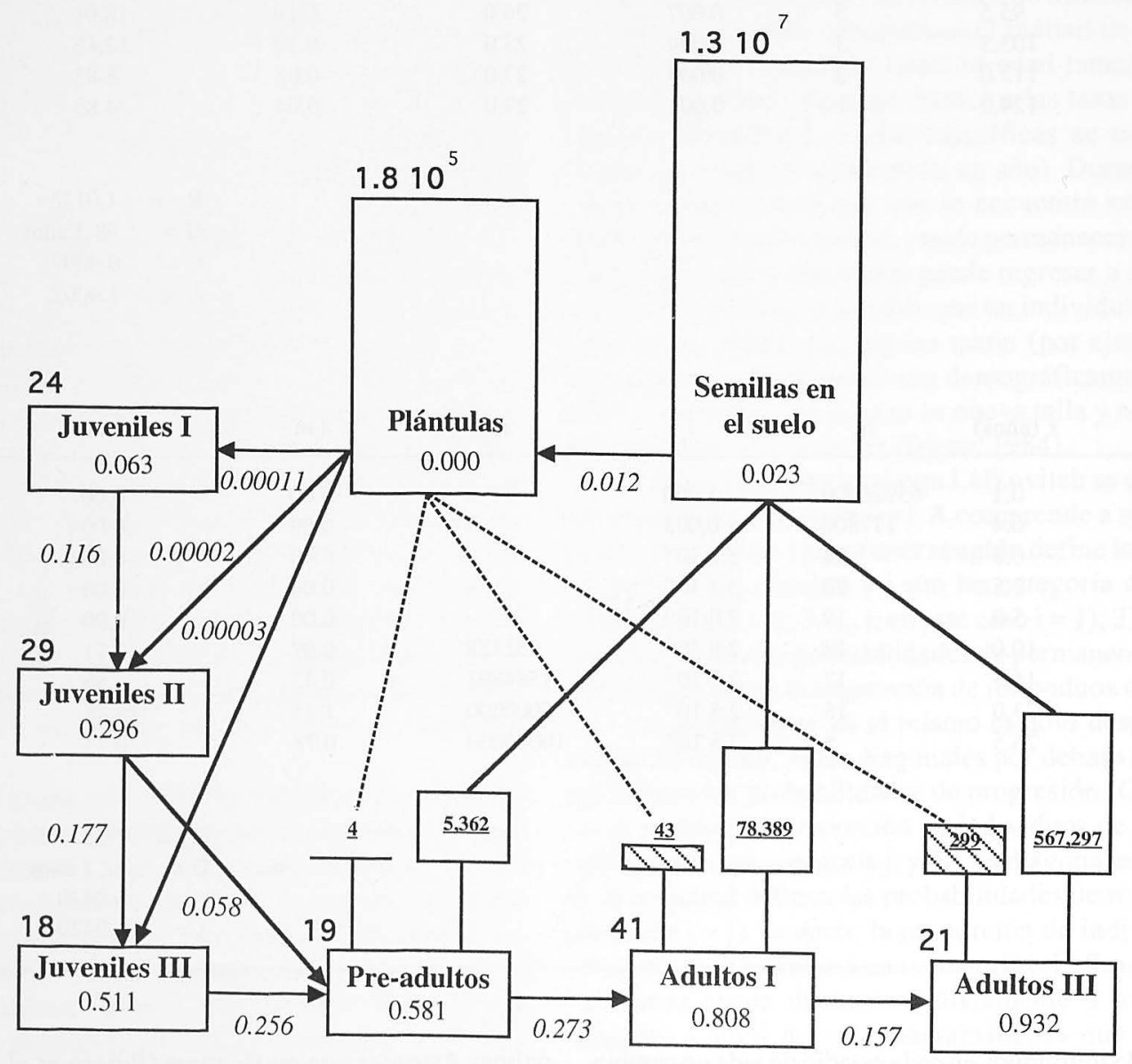

FIGURA 8. Modelos del flujo de individuos que opera en las poblaciones de (a) el árbol pionero Cecropia obtusifolia (Álvarez-Buylla, 1994), (b) la palma Astrocaryum mexicanum (Piñero et al., 1984a) y (c) el árbol del dosel superior Omphalea oleifera (Palomeque, 1988). Las flechas entre las rectángulos definen la probabilidad anual de progesión $\left(\mathrm{G}_{\mathrm{ij}}\right)$ cuyos valores se expresan en cursivas. Dentro de cada rectángulo, en la base, se indica la probabilidad anual de permanencia $\left(\mathrm{P}_{\mathrm{i}, \mathrm{i}}\right)$. Por arriba de los rectángulos pertenecientes a las categorías de individuos adultos se indica la fecundidad $\left(\mathrm{F}_{\mathrm{ij}}\right)$, cuyos valores promedios se indican subrayados. Finalmente, los números fuera de los cuadros, en la parte superior izquierda, indican la densidad de individuos por estadio de vida en 5-ha. Para la definición de los estadios de vida en cada población consultar fuentes originales. En el diagrama de C. obtusifolia las líneas punteadas (y las casillas con diagonales) indican la fecundidad en términos de plántulas producidas por año (ya que las semillas que caen en los claros germinan rápidamente, en mucho menos que un año). 
(b)

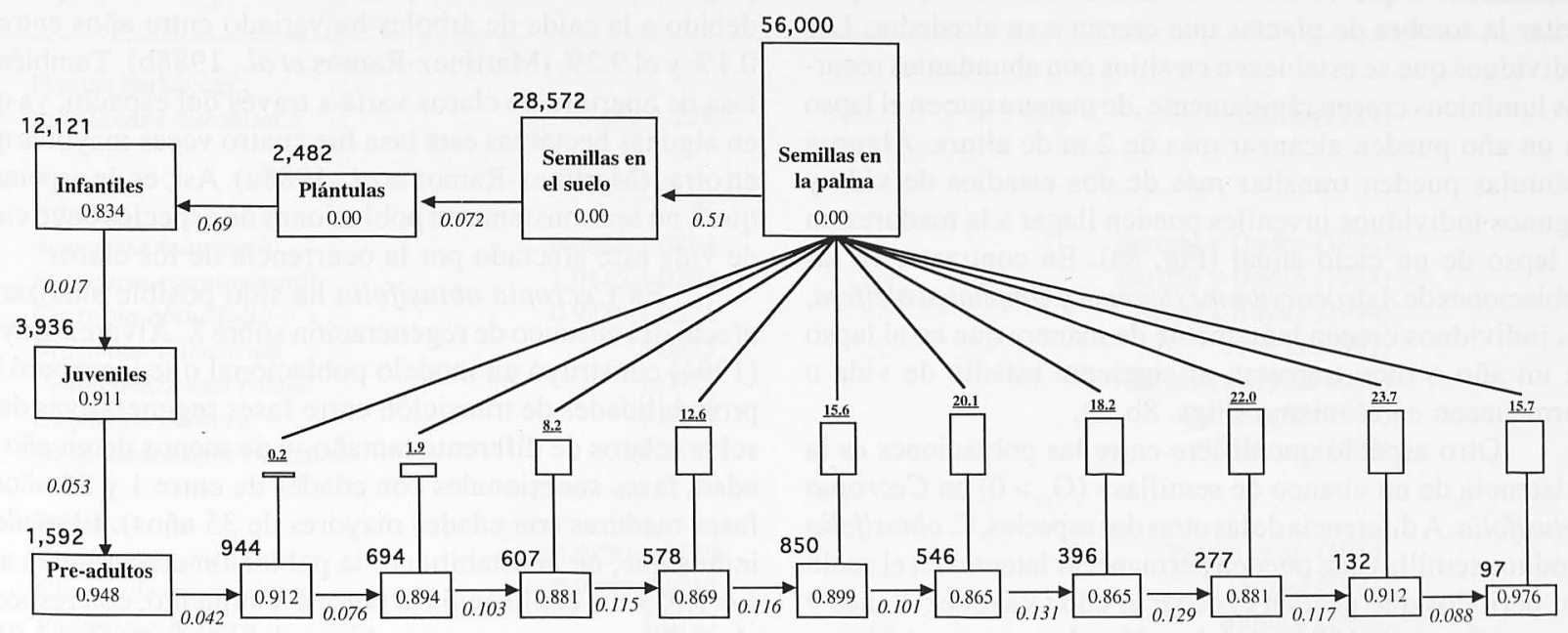

FIGURA 8b

(c)

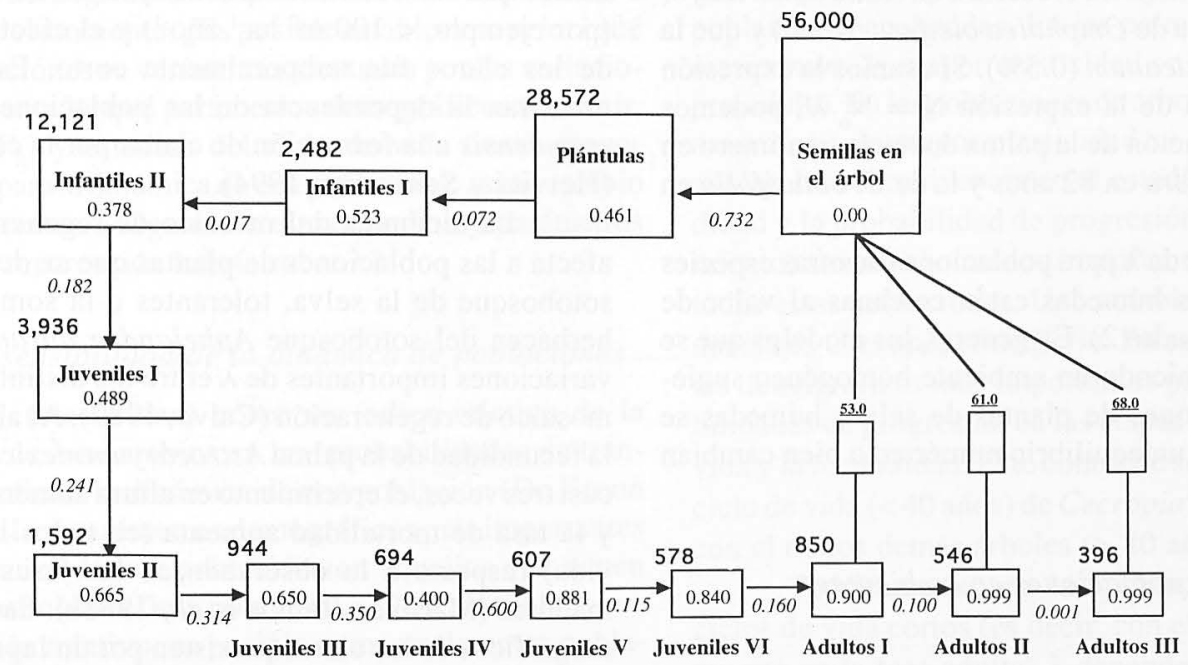

Figura 8. Continuación. 
(Álvarez-Buylla y Martínez-Ramos, 1992; Cuadro 1). Puesto que estas plantas requieren cantidades elevadas de energía lumínica para sobrevivir y crecer, las plántulas e individuos juveniles que mueren son aquellos que emergen en sitios sombreados o que no crecen lo suficientemente rápido para evitar la sombra de plantas que crecen a su alrededor. Los individuos que se establecen en sitios con abundantes recursos lumínicos crecen rápidamente, de manera que en el lapso de un año pueden alcanzar más de $2 \mathrm{~m}$ de altura. Algunas plántulas pueden transitar más de dos estadios de vida y algunos individuos juveniles pueden llegar a la madurez en el lapso de un ciclo anual (Fig. 8a). En contraste, en las poblaciones de Astrocaryum mexicanum y Omphalea oleifera, los individuos crecen lentamente de manera que en el lapso de un año o bien transitan al siguiente estadio de vida o permanecen en el mismo (Figs. 8b, c).

Otro aspecto que difiere entre las poblaciones es la existencia de un «banco de semillas» $\left(\mathrm{G}_{11}>0\right)$ en Cecropia obtusifolia. A diferencia de las otras dos especies, C. obtusifolia produce semillas que pueden permanecer latentes en el suelo por periodos que pueden exceder el año (Vázquez-Yanes y Orozco-Segovia, 1984). Así, las plántulas que se establecen en un claro provienen de semillas recién dispersadas o bien de semillas latentes de diferentes edades (Fig. 8a). Un estudio experimental indicó que por cada 100 plántulas establecidas en los claros, una proviene de las semillas que han permanecido en el banco por más de un año y el resto proviene de las que arribaron a los claros después de su apertura (Álvarez-Buylla y Martínez-Ramos, 1990; ÁlvarezBuylla y García-Barrios, 1991).

Los modelos mostrados en la Fig. 8 estiman un valor de $\lambda$ de 1.005 para Astrocaryum mexicanum (Piñero et al., 1984), de 1.009 para Omphalea oleifera (Palomeque, 1988) y de 1.014 para Cecropia obtusifolia (Álvarez-Buylla, 1994). Así, dentro de las suposiciones de estos modelos, la población de Cecropia obtusifolia crecería a un ritmo anual mayor (1.4\% por año) que la de Omphalea oleifera $(0.9 \%)$ y que la de Astrocaryum mexicanum ( $0.5 \%$ ). Si usamos la expresión $\mathrm{t}=\mathrm{Ln} 2 / \mathrm{r}$, derivada de la expresión $\mathrm{N}_{1}=\mathrm{N}_{0} \lambda^{\mathrm{t}}$, podemos calcular que la población de la palma doblaría su número en 151 años, la $O$. oleifera en 82 años y la de $C$. obtusifolia en sólo 51 años.

Estimaciones de $\lambda$ para poblaciones de otras especies de plantas de selvas húmedas están cercanas al valor de equilibrio ( $\lambda=1$; Cuadro 2). En general, los modelos que se han elaborado suponiendo un ambiente homogéneo sugieren que las poblaciones de plantas de selvas húmedas se encuentran cerca de un equilibrio numérico o bien cambian a velocidades lentas.

\section{Crecimiento de las poblaciones en ambientes heterogéneos}

Una conclusión aparente que puede surgir de la sección anterior es que la densidad de las poblaciones de selvas húmedas se mantiene constante a través del tiempo. Sin embargo, el supuesto implícito en los modelos, de que el ambiente que afecta a las poblaciones es homogéneo y temporalmente constante, se aleja de la realidad. Por ejemplo, en cinco hectáreas de la selva de Los Tuxtlas, la proporción de la selva que se abre anualmente a claros debido a la caída de árboles ha variado entre años entre el $0.1 \%$ y el $9.2 \%$ (Martínez-Ramos et al., 1988b). También la tasa de apertura de claros varía a través del espacio, ya que en algunas hectáreas esta tasa fue cuatro veces mayores que en otras (Martínez-Ramos et al., 1988a). Así, es de esperarse que $\lambda$ no sea constante en poblaciones de especies cuyo ciclo de vida esté afectado por la ocurrencia de los claros.

En Cecropia obtusifolia ha sido posible analizar el efecto del mosaico de regeneración sobre $\lambda$. Álvarez-Buylla (1994) construyó un modelo poblacional que incorporó las probabilidades de transición entre fases regenerativas de la selva (claros de diferente tamaño, y de menos de un año de edad, fases sucesionales con edades de entre 1 y 35 años y fases maduras con edades mayores de 35 años). El modelo indica que, en la estabilidad, la población crecería con una $\lambda=1.059$. La explicación al porqué $\lambda$ aumentó, con respecto al modelo que supone un ambiente homogéneo $(\lambda=1.014$, que no fue estadísticamente diferente de 1 ), es que en el modelo que simula heterogeneidad ambiental los hábitats que favorecen el crecimiento de la población de C.obtusifolia aumentan proporcionalmente con el tiempo (Álvarez-Buylla, 1994).

En la planta herbácea demandante de luz Calathea ovandensis, un modelo matricial mostró que $\lambda$ cambia con la tasa de formación de claros y con la velocidad con la que los valores demográficos observados en los claros cambian a medida que éstos se cierran (Horvitz y Schemske, 1986). $\lambda$ fue mayor que 1 cuando la tasa de apertura de claros fue rápida (por ejemplo, $200 \mathrm{~m}^{2}$ ha $^{-1}$ año-1) y el efecto demográfico causado por los claros fue prolongado, mientras que fue menor que uno cuando la tasa de apertura de claros fue lenta (por ejemplo, $<100 \mathrm{~m}^{2} \mathrm{ha}^{-1}$ año-1) y el efecto demográfico de los claros fue temporalmente corto. Estos resultados muestran la dependencia de las poblaciones de Calathea ovandensis a la formación de claros por la caída de árboles (Horvitz y Schemske, 1994).

La dinámica del mosaico de regeneración también afecta a las poblaciones de plantas que se desarrollan en el sotobosque de la selva, tolerantes a la sombra. La planta herbácea del sotobosque Aphelandra aurantiaca muestra variaciones importantes de $\lambda$ entre los distintos hábitats del mosaico de regeneración (Calvo, 1989). Al abrirse un claro, la fecundidad de la palma Astrocaryum mexicanum aumenta casi tres veces, el crecimiento en altura aumenta casi al doble y la tasa de mortalidad aumenta (en todos los estadios de vida) respecto a lo observado en las fases regenerativas maduras (Martínez-Ramos et al., 1988a). Estos efectos demográficos de los claros persisten por un lapso aproximado de diez años. Sin embargo, tales cambios demográficos no tienen efectos importantes sobre la dinámica de la población de esta palma. Un modelo matricial, similar al descrito 
CuAdro 3. Estimaciones de $\lambda$ a través de modelos de matrices de proyección lineal para poblaciones de plantas de selvas húmedas que suponen ambientes homogéneos. Cuando se muestran dos valores separados por un ión se implica que se han obtenido varias estimaciones $\lambda$ para distintas poblaciones o bien para la misma población con diferentes modelos.

Especies

$\lambda$

Fuente

Plantas herbáceas:

Aphelandra aurantiaca

0.891-1.228

Calvo (1989)

Arboles:

Araucaria hunsteinii

0.9889-1.0884

Araucaria cunninghamii

1.0115-1.0202

Cecropia obtusifolia

0.9488-1.0321

1.0635

1.0021

Pentaclethra macroloba

1.0085

Omphalea oleifera

1.0471

Enright y Ogden (1978)

Enright y Ogden (1978)

Álvarez-Buylla (1994)

Peters (1991)

Hartshorn $(1972,1975)$

Palomeque (1988)

Hartshorn (1972)

Palmas:

Astrocaryum mexicanum

0.9890-1.0120

Piñero et al. (1984)

0.9699-1.1232

Oyama (1987)

1.0125

Bullock (1980)

Podococus barterii

$1.0080-1.1995$

Durán (1992)

Thrinax radiata

$1.0925-1.1492$

Buylla (1995)

Coccothrinax readii

1.0549

anteriormente para Cecropia obtusifolia, obtuvo una $\lambda=$ 1.012, que no es diferente de aquella $(\lambda=1.011)$ obtenida suponiendo un ambiente homogéneo (Martínez-Ramos et al., 1988a).

Los casos de Cecropia obtusifolia y Astrocaryum mexicanum ilustran de qué manera especies con diferentes propiedades demográficas responden de manera distinta a variaciones del ambiente. ¿Es posible establecer a priori qué tipo de poblaciones se verían más afectadas por las variaciones del ambiente?, ¿qué parámetros demográficos (es decir, $P_{i j}, G_{i j}, R_{i j}, F_{i j}$ ) y estadios del ciclo de vida tienen mayor importancia para la dinámica de una población?, ¿si un cambio ambiental afectase a alguno de estos estadios y parámetros críticos, qué repercusión habría sobre $\lambda$ ?

\section{Análisis de sensibilidad de la dinámica de poblaciones}

Se define $e_{i j}$ (elasticidad) como un índice relativo de la sensibilidad de $\lambda$ a cambios en las probabilidades de transición que definen la dinámica de una población (De Kroon et al., 1986). Los parámetros demográficos más importantes para la dinámica de una población son aquellos que tienen la mayor elasticidad (De Kroon et al., 1986). Debido a que $\mathrm{e}_{\mathrm{ij}}$ es un índice relativo, es posible compararlo entre poblaciones de una misma especie y entre poblaciones de diferentes especies. Una pregunta que puede surgir de inmediato es: ¿especies con diferentes atributos demográficos difieren en su elasticidad a una perturbación?

Siguiendo el método de De Kroon et al. (1986), obtuvimos valores de elasticidad para las poblaciones de plantas arbóreas de selvas húmedas (Fig. 9). La probabilidad de progresión (equivalente a la sobrevivencia) en los estadios de pre-adultos y adultos es el componente demográfico más importante para la dinámica de la mayoría de las poblaciones analizadas. En las palmas, salvo Astrocaryum mexicanum, la mayor elasticidad se encontró en el estadio pre-adulto. En las poblaciones de árboles, salvo Pentaclethra macroloba, la mayor elasticidad se encontró en el estadio adulto. La sobrevivencia en el estadio de semilla, la fecundidad y la probabilidad de progresión (equivalente al crecimiento) son mucho menos importantes para la dinámica de todas estas poblaciones. Una notable excepción a esta tendencia es Cecropia obtusifolia. En este caso los componentes demográficos más importantes para $\lambda$ fueron las probabilidades de progresión en las etapas tempranas del ciclo de vida y la fecundidad. Este contraste se relaciona con el corto ciclo de vida ( $<40$ años) de Cecropia obtusifolia comparado con el de los demás árboles (> 80 años).

Teóricamente, en las poblaciones de plantas con ciclos de vida cortos (es decir, con elevada probabilidad de muerte en la fase adulta) $\lambda$ depende en mayor grado de la fecundidad y la progresión en las etapas tempranas del ciclo de vida (Silvertown et al., 1992). La dinámica de estas 

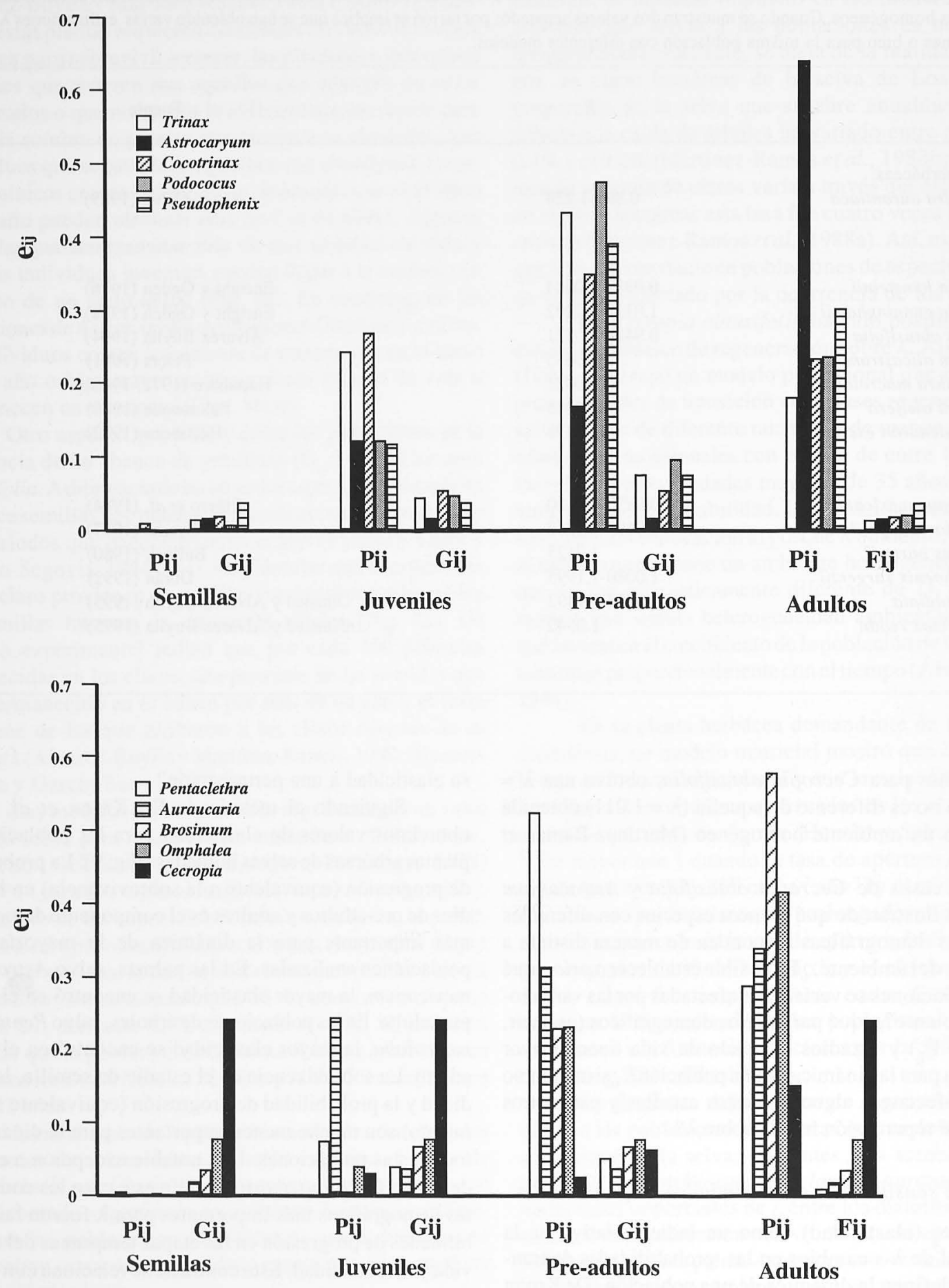

Figura 9. Valores de elasticidad obtenidos para varias poblaciones de plantas arbóreas de selvas húmedas y sub-húmedas: a) palmas y b) árboles. Estos valores fueron obtenidos analizando información encontrada en : Piñero et al. (1984) para Astrocaryum mexicanum, Enright y Ogden (1979) para Areaucaria hunsteinii, Peters (1991) para Brosimum alicastrum, Álvarez-Buylla (1995) para Cecropia obtusifolia, Olmsted y Álvarez-Buylla (1995) para Cocotrinax readii, Palomeque (1988) para Omphalea oleifera, Hartshorn (1972, 1975) para Pentaclethra macroloba y Durán (1992) para Pseudophoenix sargentii. 
poblaciones depende del abasto de semillas y el crecimiento rápido de los individuos, debido a que el tiempo para alcanzar la madurez es corto y los adultos sufren tasas rápidas de mortalidad. Por el contrario, en las poblaciones de plantas con ciclos de vida prolongados (es decir, poblaciones con baja probabilidad de muerte en la fase adulta) $\lambda$ depende en mayor grado de probabilidad de permanencia en la etapa adulta (Silvertown et al., 1992). En estas poblaciones la probabilidad que tienen los individuos juveniles y preadultos de transitar al estadio adulto es pequeña puesto que las tasas de mortalidad son elevadas en las primeras fases del ciclo de vida y el crecimiento de los individuos es muy lento. Por lo tanto, $\lambda$ se vería modificada si algún fenómeno ambiental cambiase la relación entre la tasa de mortalidad de los adultos y la probabilidad de progresión de las fases preadultas a las adultas.

Estas consideraciones teóricas también explican por qué la dinámica del mosaico de regeneración es importante para $\lambda$ en Cecropia obtusifolia pero no en Astrocaryum mexicanum. La primera especie depende de manera estricta de los claros para establecerse, crecer y reproducirse, mientras que la segunda no. Sin embargo, si se modificara la tasa de mortalidad de los adultos en la población de A. mexicanum, los efectos sobre $\lambda$ pueden ser muy importantes, como puede ocurrir cuando cambia la frecuencia de caída de los árboles del dosel (Martínez-Ramos et al., 1988a). La ocurrencia esporádica de fenómenos meteorológicos severos (por ejemplo, huracanes, ciclones, sequías severas), deslaves de tierra, epidemias y plagas pueden aumentar las tasas de mortalidad en los adultos y afectar de manera importante la dinámica de poblaciones de plantas de larga vida (Horvitz y Schemske, 1994). En la selva de la isla de Barro Colorado, Panamá, la tasa de muerte de los adultos aumentó al doble en muchas poblaciones de árboles debido a la ocurrencia de un año excepcionalmente seco ( $R$. Condit, comunicación personal). Es esperable que eventos esporádicos de ese tipo tengan gran influencia en la dinámica de poblaciones de plantas con ciclos de vida prolongados.

\section{Efectos dependientes de la densidad sobre el crecimiento de las poblaciones}

Los factores que actúan independientemente de la densidad pueden producir cambios irregulares de densidad de una población con el tiempo. Aquellos que actúan de manera dependiente de la densidad pueden producir distintos tipos de dinámicas (Begon et al., 1986). En general, cuando la tasa de crecimiento de la población es muy rápida $(\lambda>1)$ y existe un efecto severo de la densidad sobre las tasas de natalidad o mortalidad, la población puede exhibir cambios temporalmente caóticos (Begon et al., 1986). En el otro extremo, cuando la tasa de crecimiento de la población es muy lenta $(\lambda \sim 1)$ y los efectos demográficos de la densidad son débiles, las poblaciones tienden a mantenerse en una densidad que no cambia con el tiempo. Entre estos extremos puede darse una gran variedad de dinámicas (Begon et al., 1986).

A medida que una población aumenta, existe una densidad, denominada la «capacidad de carga ambiental» $(\mathrm{K})$, donde la tasa de natalidad iguala a la de mortalidad de manera que $\lambda=1$. Un aumento por encima de esta densidad crítica disminuye la cantidad de recursos por planta, de manera que la tasa de sobrevivencia, la tasa de fecundidad o ambas disminuyen sensiblemente. Por arriba de $\mathrm{K}$, la tasa de muertes supera a la de nacimientos y la densidad de la población disminuye con el tiempo. Si la densidad es menor que $\mathrm{K}$ la tasa de nacimientos supera a la de muertes y la población tiende a crecer. Este mecanismo de regulación mantiene a la población alrededor de $\mathrm{K}$ y de $\lambda=1$.

En Astrocaryum mexicanum la probabilidad de remoción de las semillas que se encuentran en el suelo aumenta con la densidad de semillas (Rodríguez-Velázquez, 1994) y la probabilidad que tiene una semilla de alcanzar el estadio de plántula aumenta cuando la densidad de semillas disminuye (J. Sarukhán et al., datos no publicados); esto se debe a que los depredadores (mamíferos) no son capaces de detectarlas cuando están muy dispersas (Rodríguez-Velázquez, 1994). Por otro lado, la probabilidad de sobrevivencia de las palmas juveniles se reduce a medida que la densidad de palmas juveniles aumenta (Martínez-Ramos et al., 1988a; Enríquez, 1990). Se desconoce la causa de tal relación. No se han detectado efectos negativos de la densidad sobre la sobrevivencia de las palmas pre-adultas y adultas ni sobre la fecundidad.

Un modelo matricial que incorporó los efectos dependientes de la densidad simuló una trayectoria asintótica de la población de Astrocaryum mexicanum hacia un valor $\mathrm{K}$ de 6,000 palmas adultas por hectárea (M. MartínezRamos et al., datos no publicados). Este valor es seis veces mayor que la densidad actual y al tiempo en el que se alcanza el equilibrio cinco órdenes de magnitud menor que aquella predicha por un modelo en los que se excluyen los efectos de densidad. Esto sugiere que en el equilibrio habría una palma cada dos metros cuadrados, lo cual sería difícil de darse ya que una palma adulta ocupa en promedio $7 \mathrm{~m}^{2}$. Tales efectos de densidad implicarían una reducción en el tamaño promedio de las palmas de tres y media veces.

De acuerdo con los resultados de este modelo, esperaríamos que la población de palmas esté actualmente creciendo. En realidad, la población creció un $6 \%$ durante 11 años en una serie de parcelas que se establecieron en 1974 (Sarukhán, Piñero y Martínez-Ramos, datos no publicados) y un $9 \%$ durante ocho años en otra parcela de 2 ha (Enríquez, 1991). Posiblemente, la ocurrencia de fenómenos severos de mortalidad esporádicos disminuyen el tamaño de la población por debajo de su nivel K. Esto no es inverosímil ya que, como se discutió anteriormente, tormentas, ciclones o sequías severas pueden producir eventos importantes de mortalidad en la población de palmas adultas.

La dinámica de poblaciones de Cecropia obtusifolia 
también es afectada por factores dependientes de la densidad (Álvarez-Buylla y Martínez-Ramos, 1992; Álvarez-Buylla, 1994). En este caso, la tasa de sobrevivencia de los adultos y de fecundidad disminuyen cuando aumenta la densidad de individuos adultos (Álvarez-Buylla, 1994). Cuando se incorporaron en un modelo matricial los efectos demográficos producidos por el mosaico de regeneración y aquellos producidos por la densidad, la población tendió con el tiempo a un valor de $\lambda=1$. Al igual que con el caso de Astrocaryum mexicanum, el modelo simuló una trayectoria de tipo asintótico de la población hacia un valor de densidad constante. También el valor de $\mathrm{K}$ (76 individuos $\geq 0.3 \mathrm{~cm}$ de dap por hectárea) fue mayor que la densidad poblacional actual (29 inds/ha). El hecho de que la tasa de apertura de claros varíe notablemente a través del tiempo (por ejemplo, en muchos años no se producen claros favorables a la regeneración de C. obtusifolia) puede provocar que la densidad de la población de C. obtusifolia varíe por debajo de K.

Otros estudios en selvas húmedas también han documentado la existencia de factores dependientes de la densidad que afectan de manera negativa la sobrevivencia de semillas, plántulas (Clark y Clark, 1984; Schupp, 1988a,b), árboles juveniles (Condit et al., 1992) y árboles adultos (Gilbert et al., 1994). Sin embargo, pocas veces se han llevado a cabo estudios formales acerca de las consecuencias de tales efectos sobre la dinámica de las poblaciones (Hubbell et al., 1990b). Al parecer, los efectos de densidad están presentes principalmente en las poblaciones de elevada densidad (Hubbell et al., 1990b; 1992). Hubbell y Foster (1986) han argumentado que algunas poblaciones de baja densidad son relictos de eventos pasados y esporádicos de colonización que, en ausencia del factor promotor de la misma, se encuentran bajo un proceso de extinción local (es decir, la tasa de mortalidad es mayor que la de natalidad). Si el proceso contrario estuviese ocurriendo en otras poblaciones de baja densidad, es decir, que la colonización apenas se iniciara, se darían poblaciones en crecimiento (la tasa de natalidad es mayor a la de mortalidad). Algunas poblaciones pueden crecer hasta un punto en el que la densidad empieza a operar negativamente sobre la sobrevivencia y/o reproducción de los individuos. En el caso de la selva de la isla de Barro Colorado, al parecer contadas poblaciones de árboles se encuentran cerca del nivel de densidad donde ocurre tal regulación y muchas fluctúan libres de los efectos dependientes de la densidad (Hubbell y Foster, 1990, 1992). Esto sugiere que la mayoría de las poblaciones de árboles se encuentran bajo un proceso de extinción o colonización y pocas se encuentran cerca de su nivel K. En Los Tuxtlas, este último caso puede ser el de Astrocaryum mexicanum y Cecropia obtusifolia.

\section{EVOLUCIÓN DE HISTORIAS DE VIDA}

Además de sus aportes ecológicos, los estudios poblacionales son la base de aquellos que tratan de entender cómo evolucionan las llamadas historias de vida de los organismos. Una historia de vida se define como el conjunto de eventos demográficos que ocurren a lo largo del ciclo de vida de un organismo y que determinan su capacidad para dejar descendientes. Aunque se han propuesto muchos atributos, en general una historia de vida puede caracterizarse con tres: la sobrevivencia, el crecimiento y la fecundidad (Stearns, 1992). Combinaciones de diferentes valores de estos atributos forman un amplia variedad de historias de vida. En ciertas condiciones ambientales, cada historia de vida tiene un valor medible en su contribución al acervo genético de una población (adecuación o aptitud biológica). Bajo la teoría de evolución por selección natural, los valores de los atributos de historia de vida que maximizan la adecuación tienen un alto valor selectivo (Stearns, 1992).

Una combinación de elevada sobrevivencia, elevada fecundidad y un rápido desarrollo puede aumentar la adecuación bajo cualquier condición ambiental. Sin embargo, estos atributos de historia de vida evolucionan en direcciones opuestas y tal estrategia óptima y universal es biológicamente irreal. Por ejemplo, si la selección favorece un aumento en la sobrevivencia, se produce una disminución en la fecundidad, en la velocidad de maduración o en ambos atributos y viceversa, un aumento evolutivo en la fecundidad puede conducir a una reducción en la longevidad. Estas relaciones opuestas, denominadas conflictos de historia de vida («life history trade-offs»), tienen su origen en mecanismos fisiológicos que regulan la asignación de energía y recursos entre las funciones de mantenimiento, crecimiento y reproducción que operan dentro de un organismo (Bazzaz y Ackerly, 1992; Stearns, 1992). Puesto que un organismo posee una cantidad limitada de recursos, la asignación hacia alguna de estas funciones necesariamente se hace a expensas de los recursos que se asignan a las otras. Así, por ejemplo, se teoriza que en un ambiente pobre en recursos la selección natural favorece a genotipos que asignan una proporción elevada de sus recursos hacia funciones que aumentan la sobrevivencia y que, consecuentemente, reducen la asignación de los mismos a las funciones reproductivas. Por el contrario, en ambientes perturbados, donde el riesgo de muerte de los adultos es alto, se presume que la selección favorece a genotipos que asignan una elevada proporción de sus recursos a la reproducción y, consecuentemente, una pequeña a las funciones de mantenimiento (Bazzazy Ackerly, 1992; Stearns, 1992).

La teoría puede evaluarse desde dos enfoques. Uno tiene que ver con la exploración del potencial de evolución que existe en una población, es decir en nivel intra-poblacional. Este enfoque implica conocer el grado de variabilidad genética existente en los atributos de historia de vida y las presiones de selección que actúan sobre estos atributos (Stearns, 1992). El otro enfoque explora los resultados de la evolución que ya ha tenido lugar; éste requiere un análisis comparativo por encima del nivel poblacional y se basa en explorar divergencias (esto es, radiación) en las historias de vida expresadas por poblaciones de especies estrechamente relacionadas (por ejemplo, especies dentro de un mismo género o familia) y convergencias entre las historias de vida 
de especies lejanamente relacionadas (por ejemplo, especies de diferentes familias u ordenes). Un proceso de radiación implicaría que a partir de la historia de vida de una especie materna surjan otras que resulten adaptativas a ambientes diferentes. Un proceso de convergencia implica que, una historia de vida que es adaptativa a un ambiente, evoluciona por analogía en especies con un bajo parentesco filogenético pero que experimentan presiones de selección similares (Stearns, 1992).

\section{Estudios a nivel intra-poblacional}

Algunos estudios han explorado las predicciones de la teoría explorando de manera correlativa la existencia de disyuntivas de atributos de historia de vida dentro de las poblaciones. Piñero et al. (1992) y Oyama y Dirzo (1988) utilizaron este enfoque para evaluar los costos demográficos asociados con la reproducción. En Astrocaryum mexicanum se encontró que, en promedio, una palma asigna alrededor del $35 \%$ del carbono asimilado en un año a la producción de semillas y estructuras reproductivas asociadas. Existió una correlación negativa entre la fecundidad presente y el valor reproductivo residual (es decir, la cantidad de semillas que se esperan producir en eventos reproductivos futuros) y entre la fecundidad presente y la sobrevivencia futura. Estas correlaciones concuerdan con las expectativas de que un alta asignación de recursos a la reproducción en un evento reproductivo disminuye energía disponible para eventos reproductivos futuros y aun para las funciones de mantenimiento que determinan la sobrevivencia del organismo (Stearns, 1992). En la palma Chamaedorea alternans, Oyama y Dirzo (1988) obtuvieron resultados semejantes; en este caso se estimó que una hembra promedio asigna en promedio el $34 \%$ de su productividad anual a un evento reproductivo. Bullock (1984) realizó en Los Tuxtlas un estudio similar con Chamaedorea ernestii-augustii.

Sin embargo, este tipo de estudios no permiten aún una exploración del potencial de evolución en los atributos de historia de vida puesto que se desconoce el grado de variación genética existente en estos atributos. En contraste, existe información demográfica que puede usarse para explorar la existencia de algunas disyuntivas de historia de vida utilizando el enfoque comparativo en nivel suprapoblacional, como se muestra a continuación.

\section{Estudios a nivel supra-poblacional}

1. Tamaño de las semillas, dispersión y la sobrevivencia de plántulas en la sombra

La dispersión de las semillas confiere a las plantas maternas una serie de ventajas en el proceso de dejar descendencia: i) puede aumentar las probabilidades de la progenie de escapar a las elevadas presiones de depredación que con frecuencia ocurren en la cercanía de la planta materna (Janzen, 1970; Dirzo y Domínguez, 1986; Clark y Clark, 1984; Schupp, 1988a, b); ii) reduce la posible interacción competitiva entre plántulas hermanas, debido a que por gravedad la mayoría de los frutos producidos por una planta materna tienden a caer apiñados bajo su copa (Dirzo y Domínguez, 1986) y iii) eleva las probabilidades de llegar a sitios con ambientes favorables al crecimiento de las plántulas (Dirzo y Domínguez, 1986; Martínez-Ramos y Álvarez-Buylla, 1995).

Posiblemente el tamaño de las semillas que producen las plantas ha resultado de un compromiso energético entre producir pocas semillas con altos recursos maternos cada una o producir muchas semillas de bajo capital materno per capita (Harper, 1977; Stearns, 1992). La primera estrategia confiere pobre dispersión pero altas probabilidades de sobrevivencia de las plántulas en ambientes lumínicamente limitantes. La segunda aumenta el potencial de dispersión de las semillas pero disminuye las probabilidades de sobrevivencia de las plántulas en la sombra (Fenner, 1985).

La Fig. 10a muestra una relación negativa entre la amplitud de dispersión de las semillas y el peso de las mismas para un grupo representativo de poblaciones de árboles de la selva de Los Tuxtlas. Evolutivamente hablando, esta relación sugiere que un aumento en la capacidad de dispersión está acompañado de una disminución en el tamaño de las semillas y viceversa. La Fig. $10 \mathrm{~b}$ muestra, por otro lado, que una disminución en el tamaño de la semilla puede acompañarse de una disminución en la probabilidad de sobrevivencia de las plántulas bajo ambientes limitantes en recursos lumínicos (Foster, 1986). El amplio ámbito de variación en el tamaño de las semillas producidas por plantas representativas de diferentes especies (ámbito de variación entre especies en peso seco: 0.0001 a 20 gr/semilla; Ibarra-Manríquez y Oyama, 1992) sugiere que han evolucionado muchas estrategias entre las extremas de amplia dispersión y pobre sobrevivencia en sombra y dispersión reducida y alta sobrevivencia en sombra.

\section{Crecimiento en claros vs sobrevivencia en sombra}

Una expectativa que emerge de la teoría es que la habilidad de las plantas para sobrevivir en la sombra limita su habilidad para crecer bajo abundancia de recursos. Existe evidencia empírica al respecto; en una muestra de más de 100 poblaciones de árboles jóvenes (de tallas entre 1 a $4 \mathrm{~cm}$ de dap) de diferentes especies, Hubbell y Foster (1992) encontraron una clara relación negativa entre la sobrevivencia en condiciones de sombra y el crecimiento en las condiciones de elevada disponibilidad de recursos lumínicos de los claros. Esta relación tiene una explicación fisiológica; los mecanismos fotosintéticos y respiratorios que permiten mantener un balance positivo de carbono en condiciones de sombra limitan la capacidad de una planta para ganar carbono en condiciones de elevada energía lumínica y viceversa (Bazzaz, 1984, 1991; Bazzaz y Ackerly, 1992).

\section{Esfuerzo reproductivo y mortalidad de adultos}

La teoría sugiere que la tasa de fecundidad varía inversamente con la tasa de mortalidad de los adultos (por lo tanto, con la longevidad) y la edad a la primera reproducción (Stearns 

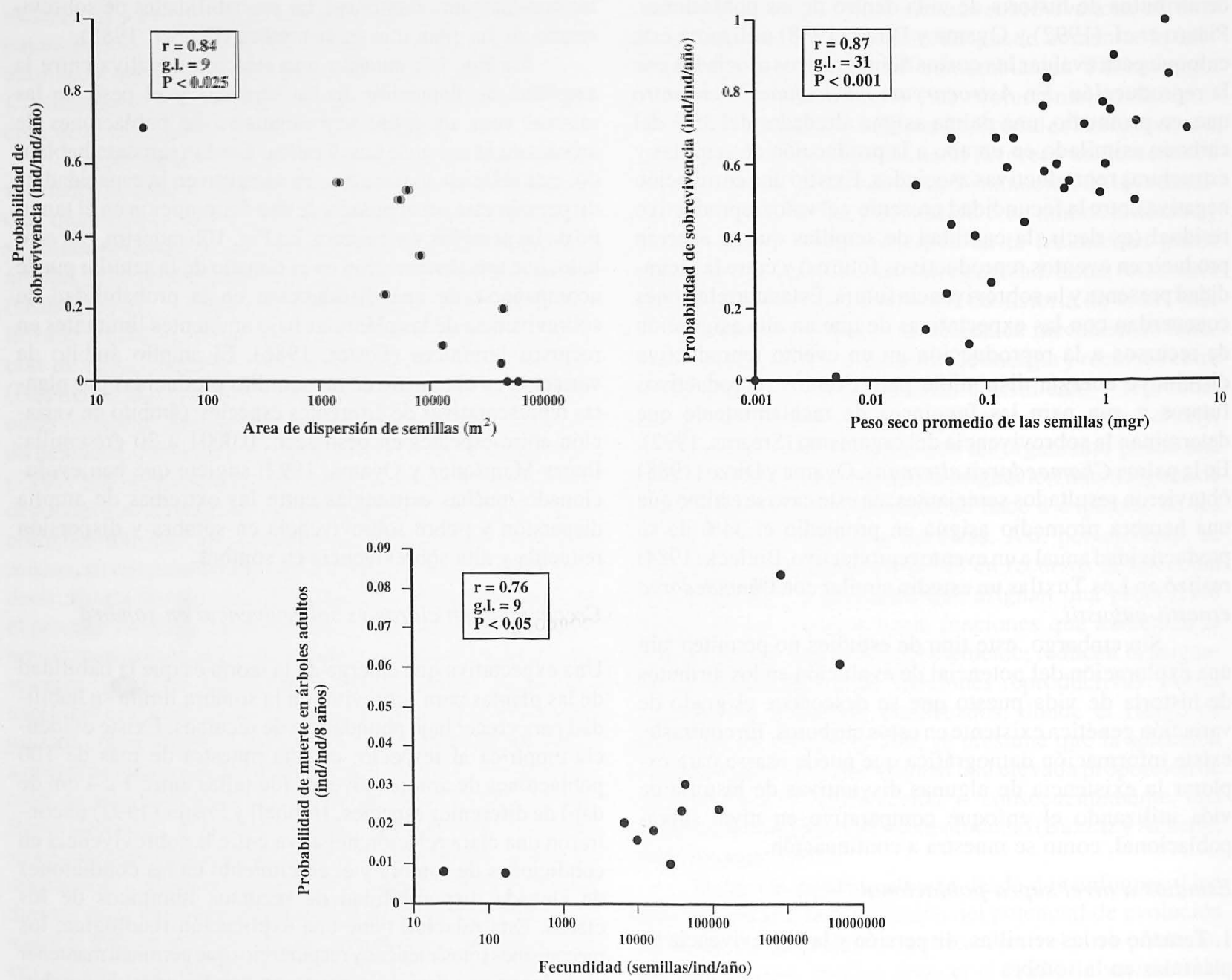

FiguRa 10. Disyuntivas entre atributos de historia de vida observada a nivel correlativo entre poblaciones de árboles de selvas húmedas. a) Amplitud de dispersión de semillas vs tamaño de la semillas (modificado de González-Méndez, 1995), b) sobrevivencia en sombra de las plántulas vs tamaño de las semillas (modificado de Martínez-Ramos, 1991), c) esfuerzo reproductivo (producción anual de semillas) vs tasas de mortalidad de adultos en ocho años (dap $\geq 10 \mathrm{~cm}$; modificado de González-Méndez, 1995). En todos los casos cada punto representa una especie. Dentro de los cuadros se muestran el vaior de correlación y el nivel de significancia correspondiente. 
1992). Una expectativa es que una elevada asignación de energía y recursos a la reproducción (asignación denominada esfuerzo reproductivo) debería disminuir la sobrevivencia y/o el crecimiento (Piñero et al., 1982; Oyama y Dirzo, 1988). Información demográfica obtenida de poblaciones de árboles que se han seguido por varios años en una parcela de 5ha en Los Tuxtlas (González, 1995; M. Martínez-Ramos, datos no publicados), nos permite explorar esta expectativa. La Fig. 10c muestra una correlación positiva entre la fecundidad (una expresión del esfuerzo reproductivo) y la probabilidad de muerte de los adultos.

\section{Radiación y convergencia evolutivas en las historias de vida}

Los casos que hasta ahora hemos explorado no tomaron en cuenta el parentesco filogenético de los taxa considerados. Por lo tanto, no se pueden separar los posibles casos de radiación de los de convergencia. El caso de las especies de la familia Moraceae ilustra uno de una aparente radiación evolutiva. En la selva de Los Tuxtlas, se ha encontrando que la historia de vida de los árboles de Trophis mexicana (altura máxima 10-15 m) es ancestral a la de los árboles Pseudolmedia oxyphyllaria (altura máxima 20-25 m), Brosimum alicastrum (altura máxima $35 \mathrm{~m}$ ), Poulsenia armata (altura máxima 35 m) y Cecropia obtusifolia (30-35 m), cuya secuenciafilogenética dentro de la familia ocurre en este orden (Martínez-Ramos, datos no publicados).

Trophis mexicana posee una historia de vida que se caracteriza por un tamaño corporal pequeño, bajas tasas de crecimiento, bajas tasas de fecundidad, madurez sexual tardía, baja respuesta a incrementos de luz y elevada sobrevivencia en la sombra. El análisis comparativo sugiere que a partir de un ancestro con este tipo de historia de vida, surgieron otras en las que la tendencia evolutiva incluyó un aumento en el tamaño corporal (ganancia en altura), una reducción en la duración del ciclo de vida, aumento en la fecundidad y tasas de crecimiento, una reducción en la capacidad para sobrevivir en la sombra y un aumento en la dependencia del ciclo de vida con hábitats ricos en recursos. El estudio sugiere que en este proceso de radiación posiblemente estuvieron involucradas fuerzas de selección que promovieron la ocupación diferencial de distintos hábitats lumínicos a través del mosaico de regeneración del bosque (M. Martínez-Ramos, datos no publicados).

Un ejemplo asombroso de convergencia evolutiva en las historias de vida es aquel representado por especies del género Cecropia de la familia Moraceae, exclusivo de selvas americanas, y muchas del género Macaranga de la familia Euphorbiaceae, exclusivo de selvas asiáticas. El hecho de que estas familias se ubican en diferentes órdenes taxonómicos muestra la pobre relación filogenética entre estos géneros. Como Cecropia, muchas especies de Macaranga muestran ciclos de vida cortos, altas tasas de crecimiento, elevada producción de semillas, dispersión por animales, elevada dependencia a hábitats ricos en luz, una morfología tan similar que a simple vista no es fácil distinguir a los árboles de uno y otro género (Whitmore, 1982). Aun esta similitud incluye aspectos ecológicos más íntimos; por ejemplo, árboles de Macaranga mantienen una relación aparentemente mutualista con hormigas (Fiala et al., 1989) como ocurre en aquellos de Cecropia (Schupp, 1986).

Por otro lado, especies arbóreas de ciclos de vida largos, pertenecientes a familias filogenéticamente distanciadas, tales como Dipterocarpaceae, Lauraceae y Myristicaceae generalmente tienen baja fecundidad, semillas grandes, tasas de crecimiento lentas, una edad tardía a la primera reproducción y elevada sobrevivencia en la sombra. Es asombroso que muchas especies pobremente emparentadas y que crecen en selvas de distintos continentes tiendan a mostrar atributos semejantes. Por ejemplo, las plántulas producidas por árboles de especies diferentes pueden agruparse de manera muy certera en cuatro grupos morfológicos generales (sensu $\mathrm{Ng}, 1978$ ) : 1) hipógeo, plántulas con cotiledones o epicótilo dentro de la testa de la semilla, funcionando como órganos de reserva, enterrados o dispuestos a nivel del suelo, 2) semi-hipógeo, igual que el anterior pero con los cotiledones expuestos por encima del suelo, 3 ) Durian, con cotiledones dentro de la testa de la semilla y pendiendo del tallo por arriba del suelo y 4) epígeo, con cotiledones de formas foliosas y fotosintéticos. El tamaño de los cotiledones y el tipo de morfología determina distintas probabilidades de sobrevivencia de las plántulas en condiciones de sombra (Martínez-Ramos y Soto-Castro, 1993). Cuando se hace una evaluación del porcentaje de la comunidad de especies arbóreas de selvas de Asia (Ng, 1978), África (Hladik y Miquel, 1990) y América (Martínez-Ramos y Soto, 1993) que representa cada tipo de morfología, es increíble la semejanza de estos porcentajes (Hladik y Miquel, 1990): 65\% (epígeo), 22\% (hipógeo), 9\% (semihipógeo) y $5 \%$ (Durian).

Los casos aquí presentados sugieren que en las selvas húmedas han existido, por un lado, presiones selectivas divergentes que han conducido a fenómenos de radiación evolutiva; por otro, los casos también sugieren la existencia de un proceso evolutivo que ha llevado a las especies hacia la convergencia en atributos de historias de vida y a la aparición de analogías morfológicas y funcionales.

\section{DEMOGRAFÍA, CONSERVACIÓN Y MANEJO DE RECURSOS NATURALES}

¿Cómo puede contribuir el estudio de las poblaciones de plantas a la conservación y el manejo de los recursos naturales que ofrece la selva húmeda? Para conservar la selva no necesariamente debemos mantenerla intacta. Es posible explotar los recursos vegetales sin alterar demasiado la estructura y dinámica de las poblaciones. Al manipular los recursos encontrados en alguna de las fases del ciclo de vida de las plantas, el objetivo será mantener, o promover, que la tasa de crecimiento poblacional $(\lambda)$ se mantenga en valores 
iguales o mayores que 1 (es decir que la población no se extinga). Por lo tanto, el diseño de técnicas de explotación de recursos debería considerar el conocimiento de la sensibilidad que tiene una población a un posible régimen de manejo.

El análisis de elasticidad (mostrado en secciones anteriores) es útil a este respecto. Como mencionamos antes, cada población posee componentes demográficos que son relativamente más importantes para su dinámica. Por lo tanto, detectando estos componentes críticos es posible establecer qué procedimientos de extracción y manejo de recursos pueden llevarse a cabo sin poner en riesgo la persistencia de la población manejada. Mediante los datos demográficos de Astrocaryum mexicanum, Omphalea oleifera y Cecropia obtusifolia obtenidos en Los Tuxtlas podemos ilustrar el procedimiento.

Como ya se discutió, bajo condiciones naturales estas especies se encuentran cerca del equilibrio poblacional o creciendo lentamente. Sin embargo, un régimen de cosecha de plantas adultas aplicado sobre una población como la de Astrocaryum mexicanum pondría en riesgo de extinción a la misma si la cosecha aumentase en más del $6 \%$ la tasa natural de mortalidad (Fig. 11a). Si la cosecha de árboles adultos fuese aplicada a una población como la de Omphalea oleifera, un régimen de cosecha que aumentase en un $15 \%$ la tasa natural de mortalidad de los árboles adultos llevaría a su extinción (Fig. 11b). Las poblaciones son mucho menos sensibles si las alteramos componentes demográficos en otros estadios de vida. Por ejemplo, podríamos cosechar más del $80 \%$ de los frutos de A. mexicanum y hasta un $95 \%$ de los de $O$. oleifera sin poner en riesgo de extinción a las poblaciones (Fig. 11a, b).

En contraste, en poblaciones como las de Cecropia obtusifolia podría extraerse una gran proporción de los adultos sin poner en riesgo la persistencia de la población, siempre y cuando aseguremos un abasto de semillas equivalente al $50 \%$ de la producción anual que ocurre de manera natural (Fig. 11c). Por el contrario, una extracción elevada (>90\% del valor natural) de las semillas (frutos) producidos, o la cosecha masiva de plantas jóvenes produciría, en el mediano plazo, la extinción de la población.

Estudios como éstos pueden ser de gran importancia para desarrollar programas de manejo y conservación de los recursos vegetales de las selvas húmedas (Peters, 1991; Álvarez-Buylla, 1994; Olmsted y Álvarez-Buylla, 1995). La dinámica de poblaciones de plantas con ciclos de vida largos es muy sensible a cambios en la tasa de mortalidad de las plantas adultas (Fig. 9). Estas poblaciones no deberían someterse a programas severos de extracción de individuos adultos (tal como ocurre con la tala selectiva de árboles). De estas poblaciones pueden extraerse de manera importante frutos (semillas), plántulas, individuos jóvenes o bien estructuras de los adultos (látex, cortezas, flores, frutos) que no afecten severamente sus probabilidades de sobrevivencia. Por el contrario, la dinámica de poblaciones de plantas con ciclos de vida cortos es más sensible a cambios en la tasa de reclutamiento de individuos jóvenes. Estas poblaciones podrían someterse a programas de extracción de individuos adultos siempre y cuando se asegure el desarrollo de las fases regenerativas de la población.

Los estudios demográficos son también importantes en la planeación de estrategias de conservación de recursos naturales, considerando la viabilidad de las poblaciones desde un punto de vista genético (Menges, 1986, 1992). Un índice primordial de tal viabilidad es el llamado «tamaño efectivo de la población» $\left(\mathrm{N}_{\mathrm{e}}\right)$, definido como el número de individuos que pueden entrecruzar material genético (Barrett y Kohn, 1991). Cuanto mayor es $\mathrm{N}_{\mathrm{c}}$ menor es el riesgo de que una población sufra pérdida de variabilidad genética debido a consanguinidad o deriva génica. La información demográfica que se tiene para Astrocaryum mexicanum permitió obtener una estimación de $\mathrm{N}_{\mathrm{c}}$ para esta especie en Los Tuxtlas de entre 227 y 436 individuos maduros (Eguiarte $e t$ al., 1993). Puesto que en las 700 ha de selva húmeda, que resguarda la Estación Los Tuxtlas, la población de esta palma tiene denees de alrededor de 1,000 individuos adultos por hectárea, puede decirse que tal población es genéticamente viable en esa reserva.

Si el tamaño efectivo de poblaciones de otras especies fuese similar al estimado para A. mexicanum, en Los Tuxtlas aquellas que tuviesen densidades poblacionales menores a un árbol adulto por cada tres hectáreas podrían sufrir problemas de deriva génica. Para estas especies sería necesario establecer reservas con tamaños por lo menos tres veces mas grandes que la de Los Tuxtlas. Reservas mucho mayores en extensión serían necesarias si el tamaño efectivo y/o las densidades de las poblaciones adultas fuesen aún menores.

\section{CONCLUSIONES GENERALES Y PERSPECTIVAS}

Hartshorn realizó en 1972 el primer estudio demográfico en una especie arbórea tropical. A partir de entonces se ha acumulado una cantidad considerable de información en el área de ecología de poblaciones de plantas tropicales (Córdova, 1985; Clark, 1994). Un centro de generación de conocimientos de esta índole se encuentra en la estación biológica de Los Tuxtlas. Sin embargo, dos décadas después aún no tenemos un panorama completo de los mecanismos que rigen la dinámica de las poblaciones de plantas en las selvas húmedas. Quizás, en parte el problema radica en la complejidad misma del sistema. Por ejemplo, como vimos, la mayoría de las poblaciones de plantas están compuestas por individuos con ciclos de vida muy largos y los factores que determinan su estructura y dinámica ocurren a escalas de décadas y varias hectáreas. No obstante tal reto podemos destacar, a manera de resumen, las siguientes conclusiones que emergen de la presente revisión:

1. Las poblaciones de plantas conforman una comunidad diversa que incluye una amplia variedad de formas de crecimiento (plantas herbáceas, palmas, 

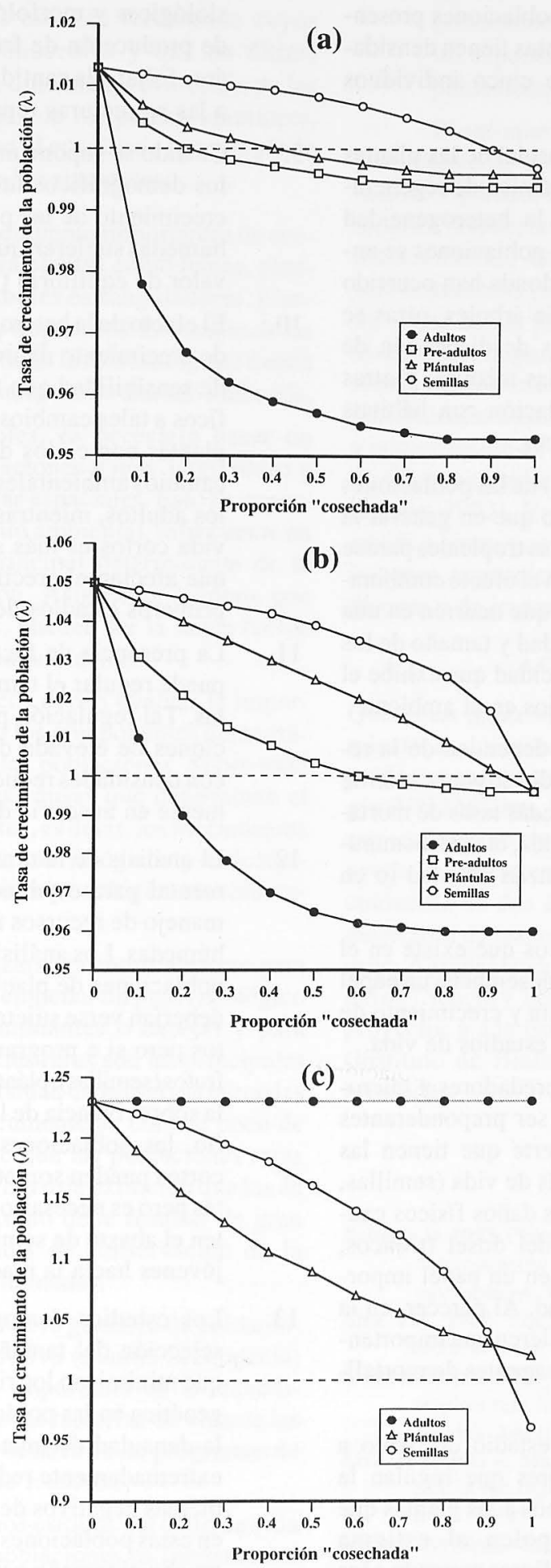

Figura 11. Efectos de posibles regímenes de cosecha de individuos o sus partes sobre la tasa de crecimiento ( $\lambda$ ) en tres poblaciones demográficamente diferentes: a) Astrocaryum mexicanum, b) Omphalea oleifera, c) Cecropia obtusifolia. En el eje de las X's se índica la proporción con la que un manejo hipotético disminuye la probabilidad de sobrevivencia (de las plántulas, individuos pre-adultos o adultos) o la fecundidad (semillas) que opera en las poblaciones bajo condiciones naturales. 
lianas, arbustos, árboles, plantas epífitas, hemi-epífitas y epífilas). La mayoría de estas poblaciones presentan baja densidad y sólo unas cuantas tienen densidades que superan la cantidad de cinco individuos adultos por hectárea.

2. La densidad y la distribución espacial de las plantas tienden a ser afectadas por la dinámica de regeneración natural del bosque y por la heterogeneidad topográfica y de suelos. Algunas poblaciones se encuentran agregadas en los sitios donde han ocurrido claros producidos por la caída de árboles, otras se agregan debido a pobres niveles de dispersión de semillas y baja depredación de las mismas, y otras más muestran agregación en relación con hábitats topográficos y edáficos específicos.

3. La estructura de edades (tamaños) de las poblaciones muestran varios patrones. Puesto que en general la relación tamaño-edad en las plantas tropicales parece ser pobre, estos patrones expresan el efecto combinado de los cambios demográficos que ocurren en una población (relacionados con la edad y tamaño de los individuos) y del grado de plasticidad que exhibe el tamaño de las plantas con cambios en el ambiente.

4. Las poblaciones de plantas que dependen de la reproducción sexual como único medio de generación de nuevos individuos presentan elevadas tasas de mortalidad en los primeros estadios de vida, la cual disminuye a medida que las plantas avanzan en edad (o en tamaño).

5. La cantidad de recursos lumínicos que existe en el sotobosque de una selva húmeda desempeña un papel fundamental para la sobrevivencia y crecimiento de las plantas durante los primeros estadios de vida.

6. Agentes bióticos, tales como depredadores y microorganismos patógenos, parecen ser preponderantes en determinar el riesgo de muerte que tienen las plantas durante sus fases iniciales de vida (semillas, plántulas y juveniles), si bien los daños físicos causados por la caída de objetos del dosel (troncos, ramas y hojarasca) tienen también un papel importante como agentes de mortalidad. Al parecer, en la fase adulta los daños físicos adquieren una importancia mayor que los bióticos como agentes de mortalidad.

7. La transición demográfica del estadio de óvulo a semilla está mediada por factores que regulan la fecundación y por agentes externos a las plantas que permiten el transporte del polen al estigma (polinizadores) o que dañan a las flores matando a los óvulos (florívoros).

8. La relación fecundidad-edad (tamaño) expresa distintas tendencias (por ejemplo, de tipo exponencial, asintótico o hiperbólico) en diferentes poblaciones.
Tales tendencias parecen depender de funciones fisiológicas y morfológicas que regulan la eficiencia de producción de frutos (y semillas) por unidad de área foliar y la cantidad de meristemos que dan origen a las estructuras reproductivas.

9. Cuando se supone un ambiente constante, los modelos demográficos utilizados para estimar la tasa de crecimiento de las poblaciones de plantas de selvas húmedas sugieren que éstas se encuentran cerca de su valor de equilibrio $(\lambda \sim 1)$.

10. El efecto de la heterogeneidad ambiental sobre la tasa de crecimiento de una población depende del grado de sensibilidad que tienen los parámetros demográficos a tales cambios. La dinámica de poblaciones de plantas con ciclos de vida largo, es más sensible a cambios ambientales que afectan la sobrevivencia de los adultos, mientras que la de plantas con ciclos de vida cortos es más sensible a cambios ambientales que afectan el crecimiento de los individuos en los primeros estadios de vida y la fecundidad.

11. La presencia de factores dependientes de densidad puede regular el tamaño de las poblaciones de plantas. Tal regulación parece ocurrir sólo en las poblaciones de elevada densidad, mientras que aquellas con densidades reducidas parecen fluctuar numéricamente en ausencia de tal regulación.

12. El análisis de la dinámica de poblaciones es fundamental para establecer criterios de conservación y manejo de recursos naturales presentes en las selvas húmedas. Los análisis de elasticidad sugieren que las poblaciones de plantas con ciclos de vida largos no deberían verse sujetas a cosechas de individuos adultos pero si a programas planeados de extracción de frutos (semillas), plántulas y estructuras que no demeriten la sobrevivencia de las plantas adultas. Por el contrario, las poblaciones de plantas con ciclos de vida cortos pueden someterse a cosechas de plantas adultas pero es necesario fomentar los medios que permiten el abasto de semillas, el desarrollo de las plantas jóvenes hacia la maduración.

13. Los estudios demográficos son importantes en la selección del tamaño de reservas de selva húmeda que minimizan los riesgos de pérdida de variabilidad genética en las poblaciones de plantas. Debido a que la densidad de muchas poblaciones de árboles son extremadamente reducidas, si se quisiera evitar problemas negativos de deriva génica y consanguinidad en estas poblaciones, estas reservas deberían exceder mucho el tamaño actual que tienen aquéllas como la de Los Tuxtlas (700 ha).

Dados estos puntos, parecería que se ha avanzado un gran trecho en el entendimiento ecológico de las poblaciones de plantas de las selvas húmedas, al menos de aquéllas 
presentes en la selva de Los Tuxtlas. Sin embargo, nuestra impresión es que estos puntos esbozan fenómenos cuyos principios y causas aún desconocemos y que en última instancia definen la estructura, dinámica y evolución de las poblaciones de plantas. Además de los puntos anteriores, algunas posibles perspectivas en el estudio de la ecología de plantas en selvas húmedas son las siguientes:

1. Existen lagunas de conocimiento importantes de ecología de poblaciones para plantas como lianas, plantas epífitas y epífilas, árboles estranguladores, plantas herbáceas terrestres y trepadoras. El estudio de las lianas parecería urgente dado la relevancia que tienen en la estructura y funcionamiento de una selva húmeda.

2. En el caso de los árboles, es necesario hacer un seguimiento de las poblaciones a muy largo plazo y a través de amplias escalas espaciales. Esto es importante ya que un solo evento ambiental, infrecuente en tiempo, puede ser el principal determinante de la dinámica de la población. Asimismo, hábitats que son espacialmente raros, pueden ser la única fuente de mantenimiento de una población.

3. Los estudios demográficos deben evaluar la importancia relativa que tienen los componentes demográficos en la dinámica de las poblaciones. Sobre todo es necesario explorar las causas que determinan el valor de estos componentes, es decir, los mecanismos funcionales (anatómicos, morfológicos y físiológi$\cos )$, y los factores genéticos y ecológicos involucrados en estos valores.

4. Los estudios deben realizarse primordialmente para especies que parecen desempeñar un papel ecológico importante (especies dominantes o claves) y para especies raras. Las especies raras son las principales constituyentes de la diversidad en las selvas húmedas $y$, sin embargo, ecológicamente se conoce poco de estas poblaciones. Puesto que las poblaciones raras pueden estar en mayor peligro de extinción que las de elevada densidad, su estudio debe resultar de gran interés para los propósitos de conservación de la diversidad de las selvas húmedas.

5. El desarrollo de estudios sobre genética de poblaciones y de biología comparativa (usando la filogenia) es un campo de estudio importante en el entendimiento de la evolución de las historias de vida de las plantas tropicales y en el desarrollo de programas de conservación y manejo de recursos.

6. La búsqueda de los estadios críticos del ciclo de vida para la dinámica de las poblaciones es fundamental para el desarrollo de programas de manejo y conservación de los recursos naturales. Es importante generar principios de conservación basados en los resultados de tal búsqueda. Los resultados hasta ahora obtenidos sugieren que es necesario tener un conoci- miento biológico detallado sobre las fases adultas en poblaciones de plantas con ciclos de vida largos y de los aspectos reproductivos y de reclutamiento en las poblaciones de plantas con ciclos de vida cortos.

El enfoque poblacional aplicado al estudio ecológico y evolutivo de las selvas húmedas, es un campo en crecimiento vigoroso. Posiblemente, de este enfoque emergerán muchas respuestas ecológicas al enigma que representa el mantenimiento de la gran diversidad de especies de las selvas húmedas (Hubbell y Foster, 1992) y un mejor entendimiento de los procesos evolutivos que dieron lugar a tal diversidad. Seguramente, en el futuro veremos cómo los frutos de los estudios poblacionales serán usados como herramientas básicas para desarrollar programas de manejo y conservación de recursos vegetales mucho más racionales de los que se aplican actualmente (Hubbell y Foster, 1992; Oyama, 1993). Esperamos que tal contribución intelectual ayude a promover la persistencia de estos extraordinarios bosques tropicales, expresión máxima de la vida en el planeta y de importancia global para la humanidad.

\section{AGRADECIMIENTOS}

Queremos hacer nuestro pleno reconocimiento y agradecimiento a los estudiantes del laboratorio de ecología de poblaciones y comunidades tropicales del Centro de Ecología (UNAM), que han colaborado en nuestros estudios. En especial agradecemos a Santiago Sinaca Colín, quien nos ha ayudado enormemente en la fase de campo. La revisión cuidadosa de dos árbitros anónimos y del Dr. Ken Oyama mejoraron de manera importante la versión final del manuscrito. Agradecemos también el apoyo que el Consejo Nacional de Ciencia y Tecnología ha brindado a varios de nuestros proyectos y a la Estación de Biología Tropical Los Tuxtlas (Instituto de Biología, UNAM) por todas las facilidades brindadas.

\section{BIBLIOGRAFÍA}

Ackerly D. 1993. Phenotypic plasticity and the scale of environmental heterogeneity: studies of tropical pioneer trees in variable light environments. Tesis doctoral. Harvard University, Massachusetts.

Aide TM. 1987. Limbfalls: a major cause of sapling mortality for tropical forest plants. Biotropica 19: 284-285.

Álvarez-Buylla E. 1994. Density dependence and patch dynamics in tropical rain forests: matrix models and applications to a tree species. American Naturalist 143: 155-191.

Álvarez-Buylla E, Martínez-Ramos M 1990. Seed bank versus seed rain in the regeneration of a tropical pioneer tree. Oecologia 84: 314-325.

Álvarez-Buylla E, García-Barrios R. 1991. Seed and forest dynamics: a theoretical framework and an example from the neotropics. American Naturalist 137: 133-154.

Álvarez-Buylla E, Martínez-Ramos M. 1992. The demography of a neotropical pioneer tree: an evaluation of the pioneer-climax paradigm. Journal of Ecology 80: 275-290.

Augspurger CK. 1984a. Light requirements of neotropical tree seedlings: 
a comparative study of growth and survival. Journal of Ecology 72: 777-795.

Augspurger CK. 1984b. Seedlings survival of tropical tree species: interactions of dispersal distance, light gaps, and pathogens. Ecology 65: 1705-1712.

Augspurger CK, 1986. Morphology and dispersal potential of winddispersed diaspores of neotropical trees. American Journal of Botany 73: 353-363.

Augspurger CK, Kelly CK. 1984. Pathogen mortality of tropical tree seedlings: experimental studies of the effects of dispersal distance, seedling density, and light conditions. Oecologia 61: 211-217.

Barrett SCH, Kohn JR. 1991. Genetic and evolutionary consequences of small population size in plants: implications for conservation. En: Falk DA, Holsinger KE, eds. Genetics and conservation of rare plants. Oxford University Press, New York. 3-30

Bawa KS. 1979. Breeding systems of trees in a tropical wet forest. New Zealand Journal of Botany 17: 521-524.

Bazzaz FA. 1984. Dynamics of wet tropical forests and their species strategies. En: M. Medina, HA. Mooney, y C. Vázquez-Yanes eds. Physiological ecology of plants of the wet tropics. Dr. Junk Publishers, Dordrech, Holanda.

Bazzaz FA. 1991. Regeneration of tropical forests: physiological responses of pioneer and secondary species. En: A. GómezPompa, TC. Whitmore y M. Hadley eds. Rainforest regeneration and management. Man and the Biosphere Series, Volume 7. UNESCO, París. 91-118.

Bazzaz FA, Ackerly D. 1992. Reproductive allocation and reproductive effort in plants. En: M. Fenner ed. Seeds: the ecology of regeneration in plant communities. C.A.B. International, Wallingford, U.K. 1-26.

Begon M., Harper JL, Townsend CR. 1986. Ecology: individuals, populations and communities. Blackwell, Oxford.

Benítez J. 1995. Ecology of seedlings in Central Amazonia forest fragments. Tesis doctoral. Cambridge University, Camdridge, Inglaterra.

Bongers F, Popma J. 1990. Leaf dynamics of seedlings of rain forest species in relation to canopy gaps. Oecologia 82: 122-127.

Bongers F, Popma J Iriarte-Vivar S. 1988. Response of Cordia megalantha Blake seedlings to gap environments in tropical rain forest. Functional Ecology 2: 379-390.

Bongers F, Popma J, Meave J, Carabias J. 1988. Structure and composition of the lowland rain forest of Los Tuxtlas, Mexico. Vegetatio 74: 55-88.

Brokaw NVL. 1985a. Treefalls, regrowth and community structure in tropical forests. En: Pickett STA, White PS, eds. Natural disturbance: the patch dynamic perspective. Academic Press, New York, 53-69.

Brokaw NVL. 1987. Gap phase regeneration of three pioneer tree species in a tropical forest. Journal of Ecology 75: 9-19.

Bullock SH. 1980. Demography of an under-growth palm in littoral Cameroon. Biotropica 12: 247-255.

Bullock SH. 1984. Biomass and nutrient allocation in a neotropical dioecious palm. Oecologia 63: 426-428.

Bullock SH, Bawa KS. 1981. Sexual dimorphism and the annual flowering pattern in Jacaratia dolichaula (D. Smith) Woodson (Caricaceae) in a Costa Rican rain forest. Ecology 62: 1494-1504.

Bullock SH, Beach JH, Bawa KS. 1983. Episodic flowering and sexual dimorphism in Guarea rhopalocarpa in a Costa Rican rain forest. Ecology 64: 851-861.

Búrquez A, Saruhinán J, Pedroza A. 1988. Floral biology of a primary forest palm, Astrocaryummexicanum Liebm. Botanical Journal of the Linnean Society 94: 407-419.

Calvo LM. 1989. Demografía y dinámica de poblaciones de Aphelandra aurantiaca (Acanthaceae) en Los Tuxtlas, Veracruz. Tesis profesional, Facultad de Ciencias, UNAM, México.

Careaga S. 1989. Efecto de la variación en el tamaño de la semilla sobre el desarrollo de plántulas de especies tropicales. Tesis Profesional. Facultad de Ciencias, UNAM, México.

Caswell H. 1989. Matrix population models. Sinauer, Sunderland.

Clark D.A. 1994. Demography of La Selva plants. En: McDade LA, Bawa KS, Hespenheide HA, Harshorn GS, eds. La Selva: ecology and natural history of a neotropical rain forest. Chicago University Press, Chicago.

Clark DA, Clark DB. 1984. Spacing dynamics of a tropical rain forest tree: evaluation on the Janzen-Connell model. American Naturalist 142:769-788.

Clark DA, Clark DB. 1985. Seedling dynamics of a tropical tree: impacts of herbivory and meristem damage. Ecology 66:18841892.

Clark DA, Clark DB. 1987a. Análisis de la regeneración de árboles del dosel en bosque muy húmedo tropical. Aspectos teóricos y prácticos. Revista de Biología Tropical 35 (sup. 1): 41-54.

Clark DB, Clark DA, 1987b. Population ecology and microhabitat distribution of Dipterix panamensis, a neotropical emergent tree. Biotropica 19: 236-244.

Clark DB, Clark DA. 1989. The role of physical damage in the seedling mortality of a neotropical rain forest. Oikos 55: 225-230.

Clark DB, Clark DA. 1991. The impact of physical damage on canopy tree regeneration in a tropical rain forest. Journal of Ecology 79:447-458.

Clauss MJ, Aarssen LW.1994. Phenotypic plasticity of size-fecundity relationships in Arabidopsis thaliana. Journal of Ecology 82: 447-455.

Chazdon R. 1988. Sunflecks and their importance to forest understory plants. Advances in Ecological Research 18: 1-63.

Coley PD. 1983. Herbivory and defensive characteristics of tree species in a lowland tropical forest. Ecological Monographs 53: 209233.

Coley PD, Bryant JP, Chapin III, F.S. 1985. Resource availability and plant anti-herbivore defense. Science 230: 895-899.

Condit R, Hubbell SH, Foster RB. 1992. Recruitment near conspecific adults and the maintenance of tree and shrub diversity in a neotropical forest. American Naturalist 140: 261-286.

Córdova B. 1985. Demografía de árboles tropicales. En: GómezPompa A, del Amo S,.eds. Investigaciones sobre la regeneración de selvas en Veracruz, México, Vol. II. Alhambra, México. 103-128.

Darwin Ch. 1857. El origen de las especies. Versión en español, 10a impresión. Diana, México.

Denslow J. 1987. Tropical rainforest gaps and tree species diversity. Annual Review of Ecology and Systematics 18: 431-451.

De Kroon H, Plaiser A, van Groenendael J, Caswell H. 1986. Elasticity: the relative contribution of demographic parameters to population growth rate. Ecology 67: 1427-1431.

De la Cruz M, Dirzo R. 1988. A survey of the standing levels of herbivory in seedlings from a Mexican rain forest. Biotropica 19:98-106.

DeStevens D. 1989. Genet and ramet demography of Oenocarpus mapora ssp. mapora, a clonal palm of a Panamanian tropical moist forest. Journal of Ecology 77: 579-596.

Dirzo R. 1984. Herbivory: a phytocentric overview. En: Dirzo R, Sarukhán J, eds. Perspectives on plant population ecology. Sinaure, Massachusetts, 141-165.

Dirzo R. 1987. Estudios sobre interacciones planta-herbívoro en «Los Tuxtlas», Veratuz. N n...ista de Biología Tropical 35 (sup. 1): 119-131. 
Dirzo R, Domínguez C. 1986. Seed shadows, seed predation and the advantages of dispersal. En: Estrada A, Fleming TH, eds. Frugivores and seed dispersal. Dr. Junk Publishers, Dordrecht, Holanda, 237-250.

Dirzo R, Miranda A. 1991. El límite boreal de la selva tropical húmeda en el continente americano: contracción de la vegetación y solución de una controversia. Interciencia 16: 240-247.

Dirzo R, Horvitz C, Quevedo H, López MA. 1992. The effects of gap size and age on the understory herb community of a tropical Mexican rain forest. Journal of Ecology 80: 809-822.

Durán R. 1992. Variabilidad intra específica y dinámica poblacional de Pseudophoenix sargentii. Tesis doctoral. UACPyP-CCH, Centro de Ecología, UNAM, México.

Eguiarte L, Búrquez A, Rodríguez J, Martínez-Ramos M, Sarukhán J, Piñero D. 1993. Direct and indirect estimates of neighborhood and effective population size in a tropical palm Astrocaryum mexicanum. Evolution 47: 75-87.

Enright N, Ogden J. 1979. Applications of transitions matrix models in forest dynamics: Araucaria in Papua New Guinea and Notophagus in New Zealand. Australian Journal of Ecology 4: 3-23.

Enriquez A. 1991. Variación espacial en los patrones demográficos de una palma tropical. Tesis profesional. Facultad de Ciencias, UNAM, México.

Estrada A, Coates-Estrada R, Martínez-Ramos M. 1985. La Estación de Biología Tropical Los Tuxtlas: un recurso para el estudio y conservación de las selvas del trópico húmedo. En: Gómez-Pompa A, del Amo S, eds. Investigaciones sobre la Regeneración de Selvas en Veracruz, México, Vol.II. Alhambra, México, 379-393.

Estrada A, Coates-Estrada R, Vázquez-Yanes C. 1984. Observations of fruiting and dispersers of Cecropia obtusifolia at Los Tuxtlas, Mexico. Biotropica 16: 315-318.

Fenner M. 1985. Seed ecology. Chapman and Hall, London.

Fiala B, Maschwitz U, Pong TY, Helbing AJ. 1989. Studies of a south east asian ant-plant association: protection of Macarang a trees by Crematogaster borneensis. Oecologia 75: 463-470.

Foster RB. 1977. Tachigalia versicolor is a suicidal neotropical tree. Nature 268: 624-626.

Foster SA. 1986. On the adaptive value of large seeds for tropical moist forest trees: a review and synthesis. The American Review 52:269-299.

Garwood NC. 1983. Seed germination in a seasonal tropical forest in Panama: a community study. Ecological Monographs 53: 159-184.

Gentry A (ed.). 1990. Four neotropical rainforests. Yale University Press, New Haven.

Gilbert GS, Hubbell SP, Foster RB. 1994. Density and distance-toadult effects of a canker disease of trees in a moist tropical forest. Oecologia 98:100-108.

González-Méndez M. 1995. Consecuencias ecológicas de la variación interespecífica en las curvas de dispersión de semillas en una selva alta perennifolia. Tesis profesional. Facultad de Ciencias, UNAM, México.

Harper JL. 1977. Population biology of plants. Academic Press, London.

Hartshorn G. 1972. The ecological life history and population dynamics of Pentaclethra macroloba, a tropical wet forest dominant and Stryphnodendron excelsum, an occasional associate. Tesis doctoral, Universidad de Washington, USA.

Hartshorn G. 1975. A matrix model of tree population dynamics. En: Golley FB, Medina E, eds. Tropical ecological systems, trends in terrestrial and aquatic research. Springer-Verlag, Berlin, 41-51.

Hartshorn G. 1978. Tree falls and tropical forest dynamics. En:
Tomlinson PB, Zimmerman MH, eds. Tropical trees as living systems. 617-638. Cambridge, London, 617-638.

Hladik A, Miquel S. 1990. Seedling types and plant establishment in an African rain forest. 261-282 En: Bawa KS, Handley M, eds. Reproductive ecology of tropical forest plants. Man and the Biosphere Series. Volume 7. UNESCO, París.261-282.

Horvitz CC, Schemske DW. 1986. Seed dispersal and environmental heterogeneity in a neotropical herb: a model of population and patch dynamics. En: Estrada A, Fleming TH, eds. Frugivores and seed dispersal. Dr. Junk Publishers, Dordrecht, Holanda, 169-186.

Horvitz CC, Schemske DW. 1994. Effects of dispersers, gaps, and predators on dormancy and seedling emergence in a tropical herb. Ecology 75: 1949-1958.

Howe HF. 1990a. Survival and growth of juvenile Virola surinamensis in Panama: effects of herbivory and canopy closure. Journal of Tropical Ecology 6: 259-280.

Howe HF. 1990b. Seed dispersal by birds and mammals: implications for seedling demography. En: Bawa KS, Handley M, eds. Reproductive ecology of tropical forest plants. Man and the Biosphere Series. Volume 7. UNESCO, París, 261-282.

Hubbell SP, Foster RB. 1983. Diversity of canopy trees in a neotropical forest and implications for conservation. En: Whitmore TC, Chadwick AC, eds. Tropical rainforestecologyandmanagement. Blackwell, Oxford, 25-41.

Hubbell SP, Foster RB. 1986. Commonness and rarity in a neotropical forest: implications for tropical tree conservation. En: Soulé $\mathrm{M}$, ed. Conservation biology: science of scarcity and diversity.Sinauer Associates, Massachusetts, 205-23.

Hubbell SP, Foster RB. 1987. La estructura espacial en gran escala de un bosque tropical. Revista de Biología Tropical (suplemento 1) 35: 7-22.

Hubbell SP, Foster RB. 1990a. Structure, dynamics, and equilibrium status of old-growth forest on Barro Colorado Island. En: Gentry AH, ed. Four neotropical forests. Yale University Press, New Haven, 522-541.

Hubbell SP, Foster RB. 1990b. Presence and absence of density dependence in a neotropical tree community. Phylosophycal Transactions of the Royal Society, London. B 330: 269-281.

Hubbell SP, Foster RB. 1992. Short-term dynamics of a neotropical forest: why ecological research matters to tropical conservation and management. Oikos 63: 48-61.

Hubbell SP, Werner PA. 1979. On measuring the intrinsic rate of increase of populations with heterogeneous life histories. American Naturalist 113: 277-293.

Ibarra-Manríquez G, Oyama K. 1992. Ecological correlates of reproductive traits of Mexican rain forest trees. American Journal of Botany 79: 383-394.

Islas M A. 1995. El efecto de la polinización, los claros y los florívoros sobre el reclutamiento en la planta herbácea Aphelandra aurantiaca (Acanthaceae) en Los Tuxtlas, Ver. Tesis profesional. Facultad de Ciencias, UNAM, México.

Janzen DH. 1969. Seed-eaters versus seed size, number, toxicity, and dispersal. Evolution 23: 1-27.

Janzen DH. 1970. Herbivores and the number of tree species in tropical forest. American Naturalist 104: 501-528.

Janzen D. 1971. Seed predation by animals. Annual Review of Ecology and Systematics 2: 465-492.

Janzen, D.F. 1976. Why bamboos wait so long to flower. Annual Review of Ecology and Systematics 10: 13-51.

Janzen DH. 1978. Seeding patterns in tropical trees. En: Tomlinson $\mathrm{PB}$, Zimmermann MH eds T.......ai trees as living systems. Cambridge Universily Press, Cambridge, 83-128. 
Kitajima K. 1994. Relative importance of photosynthetic traits and allocation patterns as correlates of seedling shade tolerance of 13 tropical trees. Oecologia 98: 419-128.

Lefkovitch, L.P. 1965. The study of population growth in organisms grouped by stages. Biometrics 21: 1-18.

Lieberman D, Lieberman M, Peralta R, Hartshorn G. 1985a. Growth rates and age-size relationships of tropical wet forest trees in Costa Rica. Journal of Tropical Ecology 1: 97-109.

Lieberman D, Lieberman M, Peralta R, Hartshorn G. 1985b. Mortality patterns and stand turnover rates in a wet tropical forest in Costa Rica. Journal of Ecology 73: 915-109.

Martínez-Ramos M. 1985. Claros, ciclos vitales de los árboles tropicales y regeneración natural de las selvas altas perennifolias. En: Gómez-Pompa A, del Amo S, eds. Investigaciones sobre la regeneración de selvas en Veracruz, México, Vol. II. Alhambra, México, 191-240.

Martínez-Ramos M. 1991. Patrones procesos y mecanismos en la comunidad de plántulas de una selva húmeda neotropical. Tesis doctoral. UACPyP-CCH, Centro de Ecología, UNAM, México.

Martínez-Ramos M. 1994. Regeneración natural y diversidad de especies arbóreas en selvas húmedas. Boletín de la Sociedad Botánica de México 54: 179-224.

Martínez-Ramos M, Álvarez-Buylla E. 1986. Gap dynamics, seed dispersal and tree recruitment at Los Tuxtlas, México. En: Estrada A, Fleming TH, eds. Frugivores and seed dispersal. Dr. Junk Publishers, Dordrecht, Holanda, 323-346.

Martínez-Ramos M, Soto-Castro A. 1993. Seed rain and advanced regeneration in a tropical rain forest. Vegetatio 107/108: 299318.

Martínez-Ramos M, Álvarez-Buylla E, Sarukhán J. 1989. Tree demography and gap dynamics in a tropical rain forest. Ecology 70: $355-358$.

Martínez-Ramos M, Sarukhán J, Piñero D. 1988a. The demography of tropical trees in the context of gap dynamics: the case of Astrocaryum mexicanum at Los Tuxtlas tropical rain forest. En: Davy AJ, Hutchings MJ, Watkinson AR, eds. Plant Population Ecology. Blackwell, Oxford, 293-313.

Martínez-Ramos M, Álvarez-Buylla E, Sarukhán J, Piñero D. 1988b. Treefall age determination and gap dynamics in a tropical forest. Journal of Ecology 76: 700-716.

Meave del Castillo J. 1987. Longevidad de las hojas de tres especies de árboles perennifolios de selva tropical húmeda. Tesis de Maestría, Facultad de Ciencias, UNAM, México.

Mendoza A, Piñero D, Sarukhán J. 1987. Effects of experimental defoliation on growth, reproduction and survival of Astrocaryum mexicanum. Journal of Ecology 75: 545-554.

Menges E. 1986. Predicting the future of rare populations: demographic monitoring and modeling. Natural Area Journal 6: 13-25.

Menges E. 1992. Stochastic modeling of extinction in plant populations. En: Fiedler PL, Jain S, eds. Conservation biology: the theory and practice of nature conservation, preservation, and management. Chapman and Hall, New York, 253-276.

Molofsky J, Augspurger CK. 1992. The effect of leaf litter on early seedling establishment in a tropical forest. Ecology 73:68-77.

Ng FSP. 1978. Strategies of establishment in Malayan forest trees. En: Tomlinson PB, Zimmermann MH, eds. Tropical trees as living systems. Cambridge University Press, Cambridge, 129-162.

Núñez-Farfán J, Dirzo R. 1988. Within-gap spatial heterogeneity and seedling performance in a Mexican tropical forest. Oikos $\mathbf{5 1}$ 274-212.

Olmsted I, Álvarez-Buylla E. 1993. Sưtainable harvesting of tropical trees: demography and matrix mndels of two palm species in
Mexico. Ecological Applications 5: 484-500.

Oyama K.1987. Demografía y dinámica poblacional de Chamaedorea tepejilote Liebm. (Palmae) en la selva de Los Tuxtlas, Veracruz (México). Tesis de maestría. Facultad de Ciencias, UNAM, México.

Oyama K.1990. Variation in growth and reproduction in the neotropical dioecious palm Chamaedorea tepejilote. Journal of Ecology 78: 648-663.

Oyama K. 1993. Conservation biology of tropical trees: demographic and genetic considerations. Environmental Update 1: 17-32.

Oyama K, Mendoza A. 1990. Effects of defoliation on growth, reproduction, and survival of a neotropical dioecious palm, Chamadorea tepejilote. Biotropica 22: 119-123.

Palomeque R. 1988. Demografía y herbivoría en Omphalea oleifera (Euphorbiaceae). Tesis de licenciatura, Facultad de Ciencias, UNAM, México.

Peñaloza J. 1985. Dinámica de crecimiento de lianas. En: GómezPompa A, del Amo S, eds. Investigaciones sobre la regeneración de selvas en Veracruz, México, Vol. II. Alhambra, México, 147-170.

Pérez-Ishiwara JR. 1990. Caracterización del microclima lumínico y sus efectos en el comportamiento reproductivo de una palma tropical. Tesis profesional. Facultad de Ciencias, UNAM, México.

Peters CM. 1991. Plant demography and the management of tropical forest resources: a case study from Brosimum alicastrum in México. En: Gómez-Pompa A, Whitmore TC, Hadley M, eds. Rain Forest Regeneration and Management. Man and the Biosphere Series, Volume 7. UNESCO, París, 91-118.

Piñero D, Sarukhán J. 1982. Reproductive behaviour and its ińdividual variability in a tropical palm, Astrocaryum mexicanum. Journal of Ecology 70: 461-472.

Piñero D, Martínez-Ramos M, Sarukhán J. 1984. A population model of Astrocaryum mexicanum and a sensitivity analysis of its rate of increase. Journal of Ecology 72: 977-991.

Piñero D, Sarukhán J, Alberdi P. 1982. Reproductive behaviour and its individual variability in a tropical palm, Astrocaryum mexicanum. Journal of Ecology 70: 461-472.

Popma J, Bongers F. 1988. The effects of canopy gaps on growth and morphology of rain forest species. Oecologia 75:625-632.

Popma J, Bongers F. 1991. Acclimation of seedlings of three Mexican tropical rain forest tree species to a change in light availability. Journal of Tropical Ecology 7: 85-97.

Rodríguez-Velázquez J. 1994. Efecto del mosaico de regeneración y la densidad sobre la remoción post-dispersión de las diásporas de una palma tropical. Tesis profesional. Facultad de Ciencias, UNAM, México.

Samper C. 1992. Natural Disturbance and plant establishment in an Andean cloud forest. Tesis doctoral. Harvard University, Massachusetts.

Sarukhán J. 1978. Studies on the demography of tropical trees. En: Tomlinson PB, Zimmerman MH, eds. Tropical trees as living sysiems. Cambridge University Press, London, 163-184.

Sarukhán J. 1980. Demographic problems in tropical systems. En: Solbrig OT, ed. Demography and evolution in plant populations. Blackwell, Oxford, 161-188.

Sarukhán J, Martínez-Ramos M, Piñero D. 1984. The analysis of demographic variability at the individual level and its population consequences. En: Dirzo R, Sarukhán J, eds. Perspectives on plant population ecology. Sinauer Ass. Inc., Sunderland, Massachusetts, 141-165.

Sarukhán J, Piñero D, Martínez-Ramos M. 1985. Plant demography: a comri......, level internretation. En: White J, ed. Studies in 
plant demography: a festschrift for John $\Lambda$. Harper. Acad. Press., London, 17-31.

Schupp EW. 1986. Azteca protection of Cecropia: ant ocupation benefits juvenile trees. Oecologia 70: 379-385.

Schupp EW. 1988a. Seed and early seedling predation in the forest understory and in treefall gaps. Oikos 51: 525-530.

Schupp EW. 1988b. Factors affecting post-disersal seed survival in a tropical forest. Oecologia 76: 525-530.

Schupp EW, Frost EJ. 1989. Differential predation of Welfia georgii seeds in treefall gaps and in the forest understory. Biotropica 21: 200-203.

Silvertown JW. 1980. The evolutionary ecology of mast seeding in trees. Biological Journal of the Linnean Society 14: 235-250.

Silvertown JW.1982. Introduction to plant populatione cology. Longman, New York.

Silvertown JW, Franco M, Pisanty I, Mendoza A. 1993. Comparative plant demography - relative importance of life-cycle components to the finite rate of increase in woody and herbaceous perennials. Journal of Ecology 81: 465-476.

Stearns SC. 1992. The evolution of life histories. Oxford University
Press, Oxford.

Terborgh J, Losos E, Ripley MP, Bolaños-Riley M. 1993. Predation by vertebrates and invertebrates on the seeds of five canopy tree species of an Amazonian forest. Vegetatio 108: 375-386.

Vázquez-Yanes C, Orozco-Segovia A. 1984. Ecophysiology of seed germination in the tropical humid forest of the world: a review. En: Estrada A, Fleming TH, eds. Frugivores and seed dispersal. Dr. Junk Publishers, Dordrecht, Holanda, 37-50.

Vázquez-Yanes C, Orozco-Segovia A.1993. Patterns of seed longevity and germination in the tropical rainforest. Annual Review of Ecology and Systematics. 24:69-87.

Vázquez-Yanes C, Orozco-Segovia A, Rincón E, Sánchez-Coronado ME, Huante P, Barradas V, Toledo JR. 1990. Light beneath the litter in a tropical forest: effect on seed germination. Ecology 71: 1952-1958.

Whitmore TC. 1982. Tropical rain forest of the far east. 2a. ed. Claredon, Oxford. 